NBER WORKING PAPER SERIES

\title{
DISCLOSURE AND THE COST OF CAPITAL: EVIDENCE FROM FIRMS' RESPONSES TO THE ENRON SHOCK
}

\author{
Christian Leuz \\ Catherine Schrand \\ Working Paper 14897 \\ http://www.nber.org/papers/w14897
NATIONAL BUREAU OF ECONOMIC RESEARCH
1050 Massachusetts Avenue
Cambridge, MA 02138
April 2009

We appreciate helpful comments from Ray Ball, Christine Botosan, John Coates, Mihir Desai, Gene Fama, Fabrizio Ferri, Luzi Hail, Anil Kashyap, Lubos Pastor, Raghu Rajan, Andrei Shleifer, Heather Tookes, Annette Vissing-Jorgensen, Luigi Zingales, and workshop participants at Duke University, ESMT Berlin, Harvard Business School, Harvard Law School, University of Chicago, University of Illinois at Chicago, Vienna University of Economics and Business, and Yale University. We thank Shanshan Cao, Wannia Hu, Avery Michaelson and Eugene Soltes for their excellent research assistance. Christian Leuz gratefully acknowledges research funding provided by the Initiative on Global Markets (IGM) at the University of Chicago Booth School of Business. The views expressed herein are those of the author(s) and do not necessarily reflect the views of the National Bureau of Economic Research.

NBER working papers are circulated for discussion and comment purposes. They have not been peerreviewed or been subject to the review by the NBER Board of Directors that accompanies official NBER publications.

(C) 2009 by Christian Leuz and Catherine Schrand. All rights reserved. Short sections of text, not to exceed two paragraphs, may be quoted without explicit permission provided that full credit, including (c) notice, is given to the source. 
Disclosure and the Cost of Capital: Evidence from Firms' Responses to the Enron Shock

Christian Leuz and Catherine Schrand

NBER Working Paper No. 14897

April 2009

JEL No. G01,G12,G14,G30,M41,M42

\begin{abstract}
$\underline{\text { ABSTRACT }}$
This paper examines the link between disclosure and the cost of capital. We exploit an exogenous cost of capital shock created by the Enron scandal in Fall 2001 and analyze firms' disclosure responses to this shock. These tests are opposite to the typical research design that analyzes cost of capital responses to disclosure changes. In reversing the tests and using an exogenous shock, we mitigate concerns about omitted variables in traditional cross-sectional disclosure studies. We estimate shocks to firms' betas around the Enron events and the ensuing transparency crisis. Our analysis shows that these beta shocks are associated with increased disclosure. Firms expand the number of pages of their annual 10-K filings, notably the sections containing the financial statements and footnotes. The increase in disclosure is particularly pronounced for firms that have positive cost of capital shocks and larger financing needs. We also find that firms respond with additional interim disclosures (e.g., 8-K filings) and that these disclosures are complementary to the $10-\mathrm{K}$ disclosures. Finally, we show that firms' disclosure responses reduce firms' costs of capital and hence the impact of the transparency crisis.
\end{abstract}

\author{
Christian Leuz \\ Graduate School of Business \\ University of Chicago \\ 5807 S. Woodlawn Avenue \\ Chicago, IL 60637-1610 \\ and NBER \\ cleuz@chicagobooth.edu \\ Catherine Schrand \\ University of Pennsylvania \\ schrand@wharton.upenn.edu
}




\section{Introduction}

The link between corporate disclosure, investor information and the cost of capital is one of the most fundamental relations in finance and accounting. Understanding this link is of substantial interest to firms that provide information to capital markets as well as to financial market regulators who mandate disclosures. Various theoretical models predict that an increase in information quality is negatively related to the cost of capital (e.g., Diamond and Verrecchia, 1991; Easley and O’Hara, 2004; Lambert et al., 2007). Similarly, the estimation risk literature suggests that higher quality information should manifest in lower systematic risk and expected returns (e.g., Barry and Brown, 1985; Coles and Loewenstein, 1988; Handa and Linn, 1993; Coles et al., 1995; Kumar et al., 2008).

Despite its importance, the empirical evidence on the link between disclosure, information quality, and the cost of capital is far from conclusive. In the estimation risk literature, studies often rely on indirect proxies for information quality such as firm age or listing period and hence there are alternative interpretations of the results (e.g., Barry and Brown, 1984; Clarkson and Thompson, 1990; Kumar et al., 2008). Studies that use more direct proxies for information quality suggest that firms with more extensive disclosures exhibit a lower cost of capital, but the evidence is mostly cross-sectional in nature (see, e.g., survey by Leuz and Wysocki, 2008). Thus, there are substantial concerns about whether these relations can be interpreted in a causal way since there are reasons to believe that the same factors that drive firms' disclosure choices could also directly affect the cost of capital. ${ }^{1}$

\footnotetext{
${ }^{1}$ For example, firms that need to raise external financing for new growth opportunities are likely to increase disclosure. However, pursuing these opportunities may also change firms' cost of capital. Separating these two effects in the cross-section is difficult.
} 
To mitigate these concerns, this paper relates an exogenous cost of capital shock - the Enron collapse - to firms' disclosure responses, which is essentially the reverse experiment to the prior literature. The events surrounding the collapse of Enron led to substantial concerns about the transparency of other U.S. firms, in particular, the quality of their financial statements and disclosures. As such, we use the revelations about Enron as an information-related shock that changed investors' beliefs about the quality (or precision) of their information and hence firms' costs of capital. The cost of capital shock in turn should lead firms to re-evaluate their disclosure policies and trigger changes in their disclosure behavior. By exploiting this natural experiment, we provide new and complementary evidence that disclosure and the cost of capital are related as predicted by theory and that firms can influence their cost of capital through firmspecific disclosures.

Our analysis focuses on the period when the news about Enron's losses and accounting irregularities hit the market in Fall 2001. The news quickly grew into widespread concerns about the transparency of U.S. corporate reporting and, in particular, about the disclosures of special purpose vehicles, off-balance sheet financing, and related-party transactions (see Appendix for details). The concerns culminated in the passage of the Sarbanes-Oxley Act in August 2002.

Our sample comprises 1,868 U.S. firms with December fiscal-year ends and required financial data from 1999 to 2001 . We measure shocks to their costs of capital around the Enron events using an econometric technique suggested by Lockwood and Kadiyala (1988) that allows for a quadratic model to estimate beta during the event window as the transparency crisis was unfolding. We focus on the shock to systematic risk in an attempt to separate cost of capital changes from updated assessments of firms' future cash flows. The quadratic form is also important because it can account for the impact of a firm's immediate responses during the event 
period on its cost of capital. ${ }^{2}$ The first part of the analysis examines firms' disclosure responses to the information-related cost of capital shock. We analyze responses in firms' annual SEC filings (Form 10-K), which occur after the event period, as well as potentially more immediate responses in 8-K filings, conference calls and earnings announcements.

We document that the cost of capital shocks over the Enron event period are associated with an increase in the firms' disclosures in their subsequent annual 10-K filings. Firms extend the number of pages in their $10-\mathrm{K}$ filings, notably the sections containing narrative discussions like Item 7, "Management's Discussion and Analysis" (MD\&A), and Item 13, "Certain Relationships and Related Transactions," as well as the financial statements and footnotes. This evidence shows that firms respond to transparency concerns and cost of capital shocks with additional disclosures. The documented link between cost of capital shocks and additional 10-K disclosures is robust to a broad set of alternative specifications and sensitivity checks to address, in particular, concerns about the validity of the beta estimates, an undue influence of the events of September 11, 2001 and updated cash-flow estimates.

For firms that experience positive beta shocks, the increase in disclosure is particularly pronounced for those that are likely to be more sensitive to their cost of capital because they have larger external financing needs and more growth opportunities. This finding is consistent with the idea that the firms most affected by the shock are most likely to respond. We also find that Arthur Anderson clients respond more strongly to the beta shocks, increasing the 10-K pages and the section on related-party transactions compared to firms with other auditors. This finding is consistent with our interpretation that the disclosures are a response to the transparency concerns created by the Enron scandal.

\footnotetext{
${ }^{2}$ However, we also show that our results are not driven by the choice of a quadratic model and that we obtain similar results from a standard market model.
} 
We also analyze disclosures made in the period immediately after the shock (hereafter "interim" disclosures). Although we do not find a significant relation between the beta shocks and the changes in the number of words in the firms' annual earnings announcements, firms do respond by increasing the number of $8-\mathrm{K}$ filings. The additional $8-\mathrm{K}$ disclosures mitigate the effects of the shock but they do not eliminate the relation between the beta shocks and disclosure in the $10-\mathrm{K}$. This finding is noteworthy because it suggests that firms view the annual $10-\mathrm{K}$ filing as a relevant disclosure mechanism to improve transparency and alleviate investor concerns, despite its lack of timeliness.

It is also conceivable that firms respond to the Enron shock with additional disclosures to avoid future litigation or to thwart a regulatory response, not to mitigate transparency concerns or to address changes in their cost of capital. This potential alternative explanation, however, does not predict the cross-sectional result, described previously, that firms with the largest disclosure responses are those that have larger external financing needs and more growth opportunities. Moreover, the notion that firms provide more but not necessarily more informative disclosures is difficult to reconcile with our final set of analyses showing that $10-\mathrm{K}$ disclosure increases are associated with abnormal volume reactions around the 10-K filing and with a subsequent decline in beta. These findings suggest that the additional disclosures are informative to investors and indeed lower the cost of capital. The latter result is important because it implies that even if the Enron scandal did not lead to cost of capital shocks per se but nonetheless triggered changes in other firms' disclosures, these disclosures are related to subsequent declines in the cost of capital.

This study contributes to the prior literature in several ways. First, by linking information-related beta shocks to firms' disclosure responses, we provide evidence that is less 
likely to reflect an omitted variable that jointly affects disclosures and the cost of capital. Prior studies generally provide evidence from cross-sectional analyses of disclosure or information levels (e.g., Botosan, 1997; Botosan and Plumlee, 2002; Easley et al., 2002; Francis et al., 2004, 2005). Similarly, the estimation risk literature generally analyzes cross-sectional differences in firm characteristics (e.g., Barry and Brown, 1984; Clarkson and Thompson, 1990). There are a few studies that examine changes in disclosure policies (e.g., Healy et al., 1999; Leuz and Verrecchia, 2000), use corporate events such as dividend changes or share repurchases (e.g., Grullon et al., 2002; Kumar et al., 2008) or exploit disclosure choices when firms access capital markets (e.g., Lang and Lundholm, 2000; Schrand and Verrecchia, 2005). But none of these studies identifies an exogenous event that changes firms' disclosure decisions (including those with a design in changes). Second, our study provides novel evidence that firms respond to transparency crises and credibility shocks in markets with increases in their disclosures. The documented disclosure increases occur shortly after the Enron scandal, but preceding the political response to the crisis, the Sarbanes-Oxley Act of 2002. Finally, we contribute to the estimation risk literature by showing that beta estimates respond to an information-related shock in predictable ways and that firms' subsequent disclosure responses reduce the impact of the beta shocks, as predicted by theory. As Kumar et al. (2008) note, such evidence is also useful in the ongoing debate about the conditional CAPM (e.g., Wang, 2003; Lettau and Ludvigson, 2001).

The paper is organized as follows. Section 2 develops the hypotheses and explains our research design exploiting the Enron events in 2001. In section 3, we define our disclosure and cost of capital proxies. Sections 4 and 5 present the results on the relation between the cost of capital shocks and firms' disclosure responses. Section 6 presents the analysis of subsequent market responses to firms' disclosure responses. Section 7 concludes the paper. 


\section{Hypothesis development and research design}

There is a long-standing literature in financial economics providing theories on the relation between investor information and the cost of capital (e.g., Diamond and Verrecchia, 1991; Easley and O'Hara, 2004; Lambert et al., 2007). An implication of these theories is that a change in investor information (e.g., its precision) leads to a change in the cost of capital. Optimal disclosure behavior in turn implies that firms respond to information-related shocks to their cost of capital by changing their disclosure policy. That is, assuming that a firm's disclosure policy is optimal at a given point in time, an information-related shock to the cost of capital should lead to a reassessment of its disclosure policy. Our main prediction is that, ceteris paribus, firms with increases in their cost of capital are likely to increase their disclosures. Furthermore, firms' disclosure increases should lead to subsequent reductions in the cost of capital. Relating firms' disclosure responses to an information-related shock as well as consequent cost of capital changes to the new disclosures should provide evidence that investor information and the cost of capital are indeed related as predicted by theory.

To test these predictions, we exploit the events at Enron as an exogenous shock to other firms' costs of capital. On October 16, 2001, Enron announced a third quarter loss of $\$ 618$ million and hinted at problems with its partnerships. On November 29, 2001, Enron announced it would restate its earnings back to 1997 and add $\$ 628$ million of debt to its 2000 balance sheet. Between these events, the SEC launched an inquiry into Enron's accounting practices and then initiated a formal investigation that included Enron's auditors, Arthur Anderson. Subsequently, Enron was removed from the S\&P 500, its debt was downgraded to junk and, eventually, it filed for bankruptcy. Appendix A.1 provides more details on the sequence of events. 
We believe that the nature of the Enron scandal is particularly suited to our analysis. The announcements revealed that Enron had been able to hide its economic and financial condition, despite compliance with SEC financial reporting requirements, which led to general concerns about U.S. financial reporting quality. As such, the Enron events likely caused investors to revise their beliefs about the precision (or quality) of their information. Furthermore, even if the Enron scandal was a symptom of a larger transparency crisis, the timing of this shock should be exogenous to other firms, which is all we need for our empirical strategy.

The following timeline provides a stylized overview of our research design and how it relates the events at Enron to our main hypothesis:

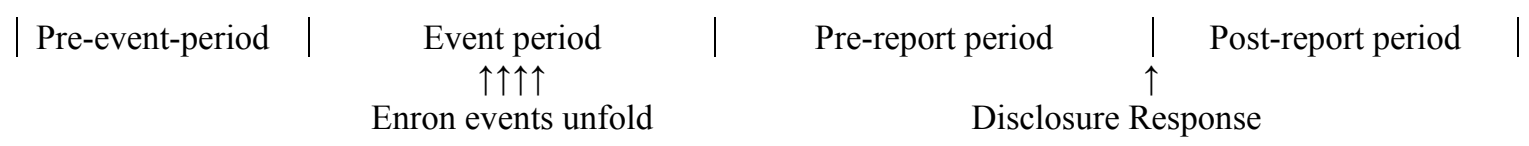

In the pre-event period, firms are in equilibrium with respect to their disclosure decisions. Investors have rational expectations over firms' future cash flows and the precision of their cash flow estimates. In the event period, the Enron scandal unfolds and leads to investor concerns about a systematic lack of transparency in U.S. financial reporting. ${ }^{3}$ As a result, investors revise their beliefs about the precision of their estimates for other firms in the economy, which changes firms' cost of equity capital. This information-related shock to the cost of capital alters firms' optimal disclosure levels and hence they adjust their disclosure policies. In response to firms' disclosures, investors revise and update their beliefs and the cost of capital adjusts again.

By relating investors' uncertainty about their information set to expected returns and hence firms' cost of capital, the estimation-risk literature provides the conceptual underpinnings

\footnotetext{
${ }^{3}$ See Appendix A.1 for citations to articles in the financial press that suggest that the market viewed the Enron scandal as indicative of widespread transparency problems in the U.S.
} 
for our analysis and, in particular, investors' reactions to the Enron shock. This literature starts from the premise that the parameters of the return-generating process are generally not known and have to be estimated (e.g., Klein and Bawa, 1976, 1977). While early studies conclude that the effects are diversifiable (e.g., Brown, 1979; Reinganum and Smith, 1983), Barry and Brown (1985) show that estimation risk is not diversifiable when information is differentially distributed across securities. Extending this finding, Coles and Loewenstein (1988) and Coles et al. (1995) show that when modeling estimation risk with respect to asset payoffs (rather than returns) estimation risk is not diversifiable and affects equilibrium returns and betas even when information is symmetrically distributed. Along similar lines, Lambert et al. (2007) analyze information structures that lend themselves more naturally to an interpretation as firm-specific disclosures about future cash flows and show that more precise disclosures move firms' cost of capital closer to the risk-free rate. This effect is again not diversifiable and manifests itself in firms' beta factors as well as the market risk premium for the economy. ${ }^{4}$ Finally, Kumar et al. (2008) analyze the effects of estimation risk on the cross section of stock returns and firms' cost of capital when investors learn from information of uncertain quality (or precision). They demonstrate that, in this situation, asset prices, firms' beta factors, and the market risk premium are estimation-risk dependent and respond to changes in the quality of information. ${ }^{5}$

Based on these theories, we expect that the Enron events led to an information-related shock to firms' cost of capital. We focus on changes in firms' beta factors for two reasons. First, the Enron events may have had an impact on investors' expectations of future cash flows

\footnotetext{
${ }^{4}$ As Lambert et al. (2008) show, the link between information and the cost of capital in Easley and O'Hara (2004) is solely driven by precision effects and very similar to the link described above, except that the analysis in Easley and O'Hara (2004) is limited to effects on firm-specific variances, which makes them diversifiable.

${ }^{5}$ Kumar et al. (2008) also provide empirical evidence that beta factors fall immediately after dividend initiations and share repurchases, i.e., corporate events that can be interpreted as reducing information uncertainty. Similarly, Barry and Brown (1984) and Clarkson and Thompson (1990) find that systematic risk of low information firms decreases as time passes (e.g., the length of their listing period) and information increases.
} 
for some firms and not just on the precision of their cash flow estimates. By focusing on changes in firms' beta factors, rather than abnormal returns, we attempt to separate cost of capital and cash flow effects. In addition, we include industry controls in all analyses and we check that our results are not driven by or sensitive to the inclusion of energy firms, for which the Enron events likely had significant cash flow effects. We also conduct a robustness analysis that uses changes in (analysts') earnings expectations as a control for updated assessments of future cash flows. Second, it is likely that the Enron events increased the market risk premium. However, shocks to the risk premium apply to the entire economy and are constant across firms. The beta factor in turn exacerbates or dampens any premium shocks for a given firm and hence appropriately captures cross-sectional differences in the cost of capital shock. ${ }^{6}$

In addition, the Enron shock could have affected investors differentially and hence could have altered information asymmetries among investors. Increased information asymmetry can raise the market risk premium demanded by investors as well as the firm-specific cost of capital (e.g., Amihud and Mendelson, 1986; Diamond and Verrecchia, 1991; Garleanu and Pedersen, 2004; Lambert and Verrecchia, 2008). However, information asymmetry effects do not alter our primary hypothesis that the Enron shock led to changes in firms' cost of capital and that, ceteris paribus, firms with increases in their cost of capital respond with an increase in disclosure.

We also make several cross-sectional predictions. We predict that firms that are more sensitive to their cost of capital because, for example, they have greater external financing needs, increase their disclosures more than less sensitive firms. We predict firms with larger credibility issues after the Enron events to respond more strongly, holding all else equal. Finally, it is possible that firms with a positive cost of capital shock respond by increasing their disclosure,

\footnotetext{
${ }^{6}$ We note that without estimating changes in the market risk premium, we cannot quantify the full magnitude of the cost of capital shock, but doing so is not necessary for a cross-sectional design.
} 
while firms with a negative shock maintain their policies. Such a response is likely if the costs of retaining disclosures are small.

To test these hypotheses in the context of the Enron events, we estimate variations of the following general specification of a cross-sectional model:

$$
\text { Change in disclosure }=\alpha+\text { beta shock }+ \text { control variables }+\varepsilon
$$

and also separate models for firms that experience a positive shock and have a higher sensitivity to their cost of capital versus all other firms. We first analyze average changes in disclosure in firms' annual 10-K filings as the shock occurred during the fourth quarter of 2001 . Thus, firms could respond in their annual filings with the SEC, which are due 90 days after year end. In the timeline above, we measure the beta shocks during the event period and then separately in the pre-report period to account for the possibility that firms respond to the shock with interim disclosures (or costly signals) during or after the event period but before filing the 10-K. Although the news about Enron's problems was a surprise to the market and occurred during a relatively short window, the event period is long enough that a firm may respond to the shock during the event period or shortly thereafter. Responses could be interim disclosures, such as conference calls or press releases, or costly financial signals, such as changes in the dividend policy or stock repurchases.

We explicitly account for such interim responses in our second set of analyses. We estimate equation (1) but include measures of changes in 8-K filings, conference call activity, and disclosures in the fourth-quarter earnings announcement as controls. We also estimate equation (1) using our various interim disclosure proxies as the dependent variable. These analyses serve three purposes. First, evidence that firms respond immediately to the cost of capital shock in predictable ways serves to increase the confidence in our shock proxies. 
Second, including these disclosures in the model of $10-\mathrm{K}$ disclosures mitigates concerns about omitted variables. If an omitted variable drives firms to increase disclosure in the $10-\mathrm{K}$, it likely also causes firms to increase other disclosure. In this case, including proxies for changes in the other disclosures in the model should attenuate the coefficient on the beta shocks, which we examine. Third, the analysis provides evidence on the role of the $10-\mathrm{K}$ filing as a disclosure instrument. The 10-K must be filed within 90 days after the fiscal-year end and hence it may not be a timely vehicle to reduce transparency concerns. At the same time, the $10-\mathrm{K}$ may be particularly appropriate to address such concerns because it contains audited financial statements and it is subject to SEC review. Thus, if more timely but potentially less credible interim disclosures are substitutes for disclosure responses in the $10-\mathrm{K}$, there may be no association between the beta shocks over the event period and firms' $10-\mathrm{K}$ responses when we control for interim disclosures. If, however, interim and 10-K disclosures are complements, the relation between the beta shock remaining after the interim response and the $10-\mathrm{K}$ disclosures is attenuated unless we control for interim responses.

In our third and final set of analyses, we invert the model in equation (1) and examine subsequent market reactions to firms' disclosures responses after the Enron shock. If the disclosures are useful to investors and increase the precision of their information, the market should respond to the release of this information and the cost of capital should decline. In performing these analyses, we also investigate the alternative hypothesis that firms increase their disclosure following the crisis merely to address concerns about litigation or to thwart future regulation. If firms provide additional disclosures that are not informative to investors (but reduce litigation risk), we do not expect the disclosure changes to be related to subsequent 
declines in the cost of capital. ${ }^{7}$ In this analysis, we measure the cost of capital response to a disclosure change, which is closer in design to traditional disclosure studies, except that we use cross-sectional variation in disclosure that is generated by an exogenous shock.

Finally, we note that there are several reasons the predicted relations may not prevail. First, the Enron crisis may not have resulted in an information-related shock for other firms, despite widespread claims in the press at the time. Second, the link between financial disclosure and the cost of capital may not exist in the way predicted by theory. Third, it is conceivable that managers do not expect that they are able to address the transparency concerns via increased disclosure, and thus they do not respond in this way.

\section{Empirical proxies and descriptive statistics}

\subsection{Sample}

The sample includes all firms on Compustat that have fiscal year ends on December $31^{\text {st }}$ and non-missing values for total assets and earnings announcement dates in each of the three years from 1999 - 2001. We exclude firms with non-December fiscal-year ends to align firms with respect to the timing of their disclosures. We exclude REITS, Limited Partnerships, Trusts and Funds from the sample. In addition, we eliminate 233 firms that likely were significantly influenced by the events of September 11, 2001. First, we exclude all airlines and insurance carriers from our sample. Carter and Simkins (2004) and Doherty et al. (2003) show that the events of September 11 had a significant effect on airlines (SIC 45) and insurance carriers, respectively. Second, we eliminate firms that file an 8-K between September 11 and the peak of our event period (November 8) that mentions the terrorist attacks, suggesting that the events of

\footnotetext{
${ }^{7}$ Note that if firms provide additional disclosures in response to the Enron debacle but not necessarily to the cost of capital shocks, our analysis of subsequent changes in the cost of capital is still useful and valid as long as the Enron shock produces exogenous variation in firms' disclosure choices.
} 
September 11 had a material impact. While our event period does not start until mid October, excluding these firms mitigates the concern that the returns and beta estimates for these firms reflect ongoing valuation adjustments associated with the terrorist attacks.

We require data for 1999 and 2000 to create control variables and also benchmarks to measure changes in disclosure. The final sample contains 1,868 firms for which we have return data to compute the cost of capital shocks, Compustat data to compute the primary control variables, and 10-K filings data to create the disclosure proxies.

\subsection{Event window}

We consider seven different window specifications to define the pre-event period, the event period, and the pre-report period (see Appendix A.2). In all cases, the pre-event window starts on May 1, 2001, which for firms with December fiscal-year ends is after the year 2000 annual report season, and runs through August 31, 2001. This period precedes the market closings caused by the terrorist attacks on September 11. These events are excluded from the event period, which starts at the earliest on October 15, 2001. The pre-report period ends either on January 15, 2002 or January 28, 2002, prior to the annual earnings announcement season. Choosing the later date increases the length of the pre-report period and hence the power to measure systematic risk, but it is more likely that the beta estimates include the effects of early earnings announcements. Similarly, the choice among the different windows involves trading off a longer event period, which allows us to more precisely measure the Enron shock, against a shorter pre-report period, which makes it more difficult to accurately measure the beta prior to the $10-\mathrm{K}$ filing.

Throughout the paper, we present results for Window 1, which is centered on November 8 and has an event-period length of 39 days. The pre-report period ends on January 15, 2002. 
The Appendix provides evidence to justify this choice. The results are robust to alternative windows and generally stronger if we focus on those windows that maximize the length of the period over which the respective betas are estimated. The post-report period is consistently defined across all analyses as May 1, 2002 to August 31, 2002.

\subsection{Disclosure proxies}

Our main proxy for a change in disclosure is the percent change in the page count of the 10-K for 2001 from $2000(\% \triangle \mathrm{PAGES})$. Page count data are from the Global Securities Information (GSI) database, which covers all SEC filings that are available in the EDGAR database. We eliminate all filings with less than 10 pages. Most of these observations are references to a fuller document and not the page count of the $10-\mathrm{K}{ }^{8}$ The page counts are for the body of the 10-K (i.e., Items 1 through 15), which includes the exhibits and financial statement schedules in Item 15. The page counts exclude separate exhibits and appendices to the 10-K filing beyond Item 15. While those exhibits and appendices could include useful information (e.g., material contracts), they are not sufficiently standardized in format and content to provide a meaningful proxy for variation in information content or disclosure.

We also measure page count changes for three key sections within the 10-K. The variable $\% \triangle \mathrm{MDA}$ is the percent change in pages for Item 7, Management's Discussion and Analysis of Results of Operations and Financial Condition (MD\&A). The variable $\% \Delta \mathrm{FS}$ is the percent change in the pages of $10-\mathrm{K}$ sections that commonly include the financial statements and notes. The sections used to create this proxy are Item 6 (Selected Financial Data), Item 8 (Financial Statements and Supplementary Data), and Item 15 (Exhibits, Financial Statement

\footnotetext{
${ }^{8}$ Fifty-six sample firms switch from (to) filing a 10-K to (from) a 10-KSB. Using a different form likely affects the page count. However, the results are virtually the same if we drop these firms.
} 
Schedules, and Reports on Form $8-\mathrm{K})$. The variable $\% \Delta$ DISCUSS is the percent change in the pages of $10-\mathrm{K}$ sections that commonly include important narrative discussions and information. The sections used to create this proxy are Item 1 (Business), Item 2 (Properties), and Item 7 (MD\&A). These three proxies for key subsections address concerns that the page changes for the entire $10-\mathrm{K}$ occur in less important parts. By combining multiple items, $\% \Delta \mathrm{FS}$ and $\% \Delta$ DISCUSS further mitigate problems associated with small numbers of pages in the individual sections and with rearranging the location of information within the 10-K, which are more likely to arise for $\% \Delta \mathrm{MDA} .{ }^{9}$

For all of the percent change variables, the benchmark is the page count in the prior year. We create an alternative proxy that uses the average of the 1999 and 2000 page counts. Results are very similar for this alternative variable and are not presented. We truncate $\% \triangle$ PAGES above the $98^{\text {th }}$ percentile and below the $2^{\text {nd }}$ percentile. For the other percentage change variables, we have manually screened for a number of issues that could produce outliers (such as rearranging of information within the $10-\mathrm{K}$ ) and hence we truncate only above the $99^{\text {th }}$ percentile and below the $1^{\text {st }}$ percentile to conserve sample size. ${ }^{10}$ Winsorizing rather than truncating the variables yields similar results.

Table 1, Panel A reports descriptive statistics for the page count variables. The average $10-\mathrm{K}$ in 2001 has 64 pages $\left(\right.$ PAGES $\left._{2001}\right)$, which is almost a $17 \%$ increase over 2000 . This increase is statistically different from zero and far exceeds the average page change from 1999 to

\footnotetext{
${ }^{9}$ For all three variables, we attempt to exclude observations that appear to have rearranged the location of information within the 10-K. Observations that report an item in the current year that was incorporated by reference in the previous year (or vice versa) are eliminated under this criterion. We identify observations that potentially rearranged the $10-\mathrm{K}$ using various data filters. For these observations, we examine the $10-\mathrm{K}$ to verify that disclosures within the $10-\mathrm{K}$ were rearranged across various sections.

${ }^{10}$ Truncating the percentage change in total pages at the $99^{\text {th }}$ and $1^{\text {st }}$ percentile does not materially alter our results. However, the 43 additional observations that are gained due to the milder truncation at the $1 \%$ level are flagged by common outlier procedures. The inspection of these observations for the $10-\mathrm{K}$ part analysis also confirms this assessment, which is why we choose to truncate at the $98^{\text {th }}$ and $2^{\text {nd }}$ percentile.
} 
2000, which equals only 3.4\% (untabulated). The difference between the increase from 1999 to 2000 and the increase from 2000 to 2001 is statistically significant, suggesting that firms significantly expanded their 10-K filings in 2001 beyond the normal rate.

We investigate whether this increase in pages could be due to new disclosure requirements or accounting standards. For the fiscal 2001 reporting year, a search of SEC actions affecting 10-K reporting yields two noteworthy changes. First, the SEC required firms to include an additional table in the $10-\mathrm{K}$ related to components of its equity compensation plan. In terms of page increases, this requirement should have increased 10-K filings of all firms by one page. Second, the SEC issued new guidance for the MD\&A suggesting that firms pay particular attention to discussions of off-balance-sheet arrangements, certain investment trading activities and related-party transactions. This guidance appears to be a direct response to the issues that arose for Enron. In addition, the FASB issued three new accounting standards during the period. ${ }^{11}$ All of the new standards likely affected only the disclosures of firms that had an impairment loss on their assets. Such losses are generally reflected as special items in the income statement. We therefore check that our results are robust to a specification that controls for special items in Section 4.2. In sum, it seems unlikely that the substantial increase in $10-\mathrm{K}$ disclosures from 2000 to 2001 is primarily the result of new accounting or disclosure requirements. But even if new requirements were the primary impetus, our analysis that relates cross-sectional variation in the new disclosures to firms' cost of capital shocks is still valid as long as firms' responses to the new standards are not also closely aligned with the beta shocks.

\footnotetext{
${ }^{11}$ Statement of Financial Accounting Standards (SFAS) No. 142, "Goodwill and other intangible assets;" SFAS No. 143, "Accounting for asset retirement obligations;" and SFAS No. 144, "Accounting for the impairment or disposal of long-lived assets."
} 
Turning to the sub-sections of the 10-K filing, the MD\&A section in 2001 has on average 13.3 pages, which is a $39 \%$ increase over 2000 . The section with narrative discussions (financial tables and footnotes) has on average 27 (34) pages, which represents an increase of 22\% (18\%) over year 2000. The MD\&A, narrative, and financial sections are longer than in 2000 for over $75 \%$ of the sample observations.

Because the Enron scandal involved special purpose vehicles and partnerships that were run by corporate insiders, we also create a proxy for disclosure changes about related-party transactions. In doing so, we face two challenges. ${ }^{12}$ First, while the $10-\mathrm{K}$ requires disclosures on related-party transactions (Item 13), firms generally satisfy this requirement with a reference to their proxy statement. We therefore examine both the $10-\mathrm{K}$ and the proxy statement and select the page count from the appropriate document for each year before computing a change. Second, disclosures on related-party transactions are often only one or two pages long, which can create a small-denominator problem when computing percentage changes. Moreover, it creates the issue that changes of plus or minus one page can produce substantial percentage changes, even though they are essentially measurement error. For example, a one-page related-party section that starts at the top of a page is counted as one page, but if it starts in the middle of the page next year, it may count as two pages. We therefore classify page changes of -1 and +1 as a zero change.

After these adjustments, we compute the percentage change in the number of pages relative to the fiscal 2000 related-party disclosure section (\% $\%$ REL_PAR $)$. The page counts are derived from the $200110-\mathrm{K}$ or the proxy statement with a filing date between December 31 , 2001 and June 30, 2002. We delete extreme percentage changes that are in the $1^{\text {st }}$ or the $99^{\text {th }}$

\footnotetext{
${ }^{12}$ In addition, there is the issue that a very meaningful (but short) disclosure may be to simply state that the firm has or had no related-party transactions.
} 
percentile. Table 1, Panel A shows that the average related-party disclosure has 5 pages, but the median is equal to one page only. From 2000 to 2001, the related-party disclosures increase by $19.4 \%$ which is statistically different from zero.

Our next disclosure proxy is the change in the number of words of the fiscal 2001 earnings announcement relative to the fiscal 2000 earnings announcement (\% $\%$ WORDS). The number of words in each announcement is determined based on a manual search of earnings announcements for our sample firms on Dow Jones Interactive. We use only announcements on Business Wire or PR Newswire, as these two sources furnish unmodified press releases. We delete extreme changes in the word count that are in the $1^{\text {st }}$ and $99^{\text {th }}$ percentile. Panel A of Table 1 reports that the average earnings announcement has 2,003 words $\left(\mathrm{WORDS}_{2001}\right)$, which is a $15.5 \%$ increase over the number of words in the prior year fourth-quarter earnings announcement.

The next disclosure proxy is constructed from 8-K filings. Firms are required to use the form $8-\mathrm{K}$ to notify investors of any unscheduled material event that is important to shareholders or the SEC. The SEC defines required reportable events (e.g., shutting down a plant), and it also requires more generally that firms use the $8-\mathrm{K}$ form to disclose material information and to update any information provided in previous SEC filings. Short-window abnormal returns around 8-K filings suggest that they are informative (e.g., Beneish et al., 2005). In our context, 8-K filings could be used to respond to the Enron shock and alleviate transparency concerns. ${ }^{13}$

\footnotetext{
${ }^{13}$ For example, on December 5, 2001, American Express filed an 8-K, which simply reported: "In view of the situation involving Enron, the company is analyzing its exposure, but preliminarily believes any impact will not be material." Another 8-K followed on February 6, 2002 and stated: "First, in terms of the financial impact of Enron's bankruptcy, back in early December we filed an 8-K indicating that we preliminarily believed the impact from Enron would not be material. Having now completed our review, this statement is still true. Second, we have also reviewed our business and accounting practices in light of Enron's recent issues. Based on this review, we can see no parallels between our businesses and what we understand the practices were at Enron. Here are a few specifics."
} 
We count each firm's 8-K filings during the period from October 15, 2001, which is the beginning of our event period using Window 1, to March 31, 2002 and the same period one year earlier (8KCOUNT). In these counts, we exclude filings related to the terrorist attacks on September 11, deleting those that refer to this date or include related words like "terrorist." We then compute the difference in the $8 \mathrm{~K}$ counts from 2000 to 2001 ( $\Delta 8 \mathrm{KCOUNT})$. We set all differences that are larger than three in absolute value equal to 3 and -3 , respectively. Table 1 , Panel A shows that sample firms file on average about one 8-K during the period, although the median number of filings is zero. Excluding 8-K filings related to the events of September 11, the average change in the number of filings is close to zero.

Our last disclosure proxy is based on changes in the number of conference calls. As for the 8-K filings, we count the number of conference calls from October 15, 2001 to March 31, 2002 (CONFCALL) and compute the difference relative to the same window the year earlier $(\triangle \mathrm{CALL})$. Increases (decreases) that are larger than three in absolute value are set equal to 3 (3). Table 1, Panel A shows that, on average, firms hold one conference call over the measurement period and the number of calls decreases slightly relative to the prior year.

Table 1, Panel B presents descriptive statistics for the control variables in the analyses. We use proxies for firm characteristics that are commonly viewed as determinants of firms' disclosures, i.e., firm size, performance, financing needs and growth opportunities (e.g., Lang and Lundholm, 1993; Leuz and Wysocki, 2008). We truncate all control variables at the $1^{\text {st }}$ percentile and the $99^{\text {th }}$ percentile and measure them as of the beginning of the fiscal year, unless noted otherwise. In untabulated regressions, we confirm that the levels of our disclosure proxies exhibit meaningful associations with the control variables.

The 8-K continues with a discussion of special purpose entities, off-balance-sheet financing, and employee conflict of interest, all three of which were problems at Enron. 


\subsection{Cost of capital shocks}

To construct measures of systematic risk in the pre-event period, the event period, and the pre-report period, we employ a regime-switching model suggested by Lockwood and Kadiyala (1988). The method, which nests traditional methods, permits event-induced changes in systematic risk and provides period-specific beta estimates, which we then use to construct cost of capital shocks. Separately, we estimate the post-report period beta after the annual report season from May 1, 2002 to August 31, 2002 using a standard market model.

Following Lockwood and Kadiyala (1988) and Cyree and DeGennaro (2002), the model specification is:

$$
\begin{gathered}
R_{i t}=a_{i}+b_{i t} R_{m t}+\varepsilon_{i t} \\
b_{i t}=b_{i 1}+b_{i 2}(T 1-t)(t-T 2) D 1_{i t}+b_{i 3}\left[(T 2-T 1) D 2_{i t}+(t-T 1) D 1_{i t}\right]
\end{gathered}
$$

where $R_{i t}$ is the daily holding period return for firm i from CRSP on day $\mathrm{t}$ (including dividends) and $R_{m t}$ is the value-weighted return on the market from CRSP for day t. Systematic risk varies as a function of the trading day $\mathrm{t}$ (equation B2). T1 and T2 define the event period. They are specified as the number of trading days in the event period relative to day t. For window 1, our event period extends from October 15 through December 5 (inclusive), which contains 39 CRSP trading days, and it is centered on November $8(t=0)$, with $\mathrm{T} 1$ set at -19 and $\mathrm{T} 2$ set at +19 . D1 and D2 are indicator variables that equal one if a trading day falls into the event period or the pre-report period, respectively. ${ }^{14}$

\footnotetext{
${ }^{14}$ The event window includes the third quarter earnings announcement period. We repeat the estimation excluding return observations on the earnings announcement date and the previous day. The estimates of $\hat{b}_{i 1}$ and $\hat{b}_{i 3}$ are virtually identical. The exclusion of returns on these days has a bigger impact on $\hat{b}_{i 2}$ but even then it is economically small (at the $5^{\text {th }}$ digit) and the estimates are not significantly different. The results presented in the paper are based on the estimates that include the returns on the third quarter earnings announcement date.
} 
From the model parameters, we create separate cost of capital measures for the pre-event, event, and pre-report periods. First, systematic risk for the pre-event period (BETA_PRE) is equal to $\hat{b}_{i 1}$. This parameter is a constant throughout the pre-event period. This estimate serves as a benchmark for the firm's beta prior to the transparency shock. During the event period, when $\mathrm{D} 1=1$ and $\mathrm{D} 2=0$, systematic risk is determined by the parameter estimates for $\hat{b}_{i 1}, \hat{b}_{i 2}$, and $\hat{b}_{i 3}$. The quadratic specification allows for the initial shock to the cost of equity capital to be either positive or negative. The parameter $\hat{b}_{i 2}$ captures the direction and the curvature of the initial shock. The quadratic specification also allows for (but does not require) a recovery of the shock during the event period. Thus, the quadratic form of the regime-switching model can accommodate the impact of interim disclosure responses on firms' costs of capital during the event period. We confirm in Section 5 that the curvature and firms' interim disclosures are, in fact, related as hypothesized.

We compute the event beta (BETA_EVT) at day $\mathrm{t}=0$, which represents the peak given the quadratic specification. This beta is computed from (B2) by setting $t=0$ and recognizing that our event window is symmetric and hence $\mathrm{T} 2=-1 * \mathrm{~T} 1$ :

$$
\hat{\beta}_{i 2}=\hat{b}_{i 1}+\hat{b}_{i 2}(T 2)^{2}+\hat{b}_{i 3} T 2
$$

After the shock and during the pre-report period, systematic risk is given by:

$$
\hat{\beta}_{i 3}=\hat{b}_{i 1}+\hat{b}_{i 3}(T 2-T 1)
$$

Like the pre-event beta, the pre-report or remaining beta (BETA_REM) is constrained to be a constant across the period. 
To provide intuition for the parameters, Figure 1 illustrates time-series patterns of systematic risk for the pre-event period, the event period, and the pre-report period under alternative estimates for $\hat{b}_{i 2}$ and $\hat{b}_{i 3}$. Panels A through C illustrate the behavior of systematic risk in the cases of HIGH positive $\hat{b}_{i 2}$ (equals 0.100 ), LOW positive $\hat{b}_{i 2}$ (equals 0.002 ), and negative $\hat{b}_{i 2}$ (equals -0.002), respectively. Within each panel, we present estimates of systematic risk in the pre-report period for five levels of $\hat{b}_{i 3}$. In all three panels, the pre-event beta estimates are constant over the period. The pre-report betas also are constant throughout the period, but they can be higher or lower than the pre-event beta. When $\hat{b}_{i 3}$ is positive, the pre-report beta is higher than the pre-event beta. Furthermore, the pre-report beta can be higher than the event beta, even when $\hat{b}_{i 2}$ is positive, if $\hat{b}_{i 3} T 2>\hat{b}_{i 2}(T 2)^{2}$.

Before computing the shocks, we truncate the beta estimates in each period at the $1^{\text {st }}$ and the $99^{\text {th }}$ percentile. In addition, we drop observations for which the beta appears to unstable as indicated by a significantly positive estimate in the pre-event period but a significantly negative estimate in the post period (or vice versa). This criterion eliminates 20 observations but does not materially affect our results. We then use beta level estimates over the three periods to create proxies for changes in firms' cost of capital (i.e., shocks) as a result of the Enron events. We define the initial shock (INIT_SHOCK) as the difference between the event beta in (B3) and the pre-event beta: INIT_SHOCK $=$ BETA_EVT - BETA_PRE. Recalling that BETA_EVT is the peak of the quadratic beta estimate, the initial shock metric captures the extent to which a firm's systematic risk increases during the Enron crisis. We define the remaining shock (REM_SHOCK) as the difference between the pre-report beta and the pre-event beta, i.e., REM_SHOCK = BETA_REM - BETA_PRE. The remaining shock captures the extent to which 
a firm's systematic risk continues to be elevated after the Enron crisis and the firm's immediate responses, but before the $10-\mathrm{K}$ is filed.

Table 2, Panel A, provides descriptive statistics for the parameter estimates, systematic risk and the beta shocks based on Window 1. The average pre-event beta for the sample firms is 0.670 (and close to 1 computing a value-weighted average). The shock variables exhibit considerable cross-sectional variation and a reasonable parameter range. As the average (valueweighted) beta for the economy is by definition equal to 1 at any given point in time, it is expected that the average shock is relatively close to zero. Nevertheless, firms with negative beta shocks may experience an increase in the cost of capital if the equity risk premium increases. Regardless, the beta shocks provide an appropriate cross-sectional ranking.

Panel B reports the average initial shock (INIT_SHOCK) and the average remaining shock (REM_SHOCK) by 2-digit SIC industry code and the proportions of positive observations in each industry. The industries with the largest initial shocks are Furniture (SIC 25), Building products (SIC 15), and Auto dealers/gas stations (SIC 55). Industries that have a high proportion (i.e., greater than $80 \%$ ) of firms with positive remaining shocks are Furniture (SIC 25), Building/Construction (15), Personal services (72), Apparel (SIC 23), Oil and gas extraction (SIC 13), Motion Pictures (78), and Water transportation (SIC 44). In the Appendix, we further characterize the shock variables and conduct various validity checks.

\section{Analysis of disclosure responses to the cost of capital shocks}

\subsection{Main results}

The first analysis relates the percentage changes in the 10-K page count to the cost of capital shocks. We implement the following specification of the general model in equation (1): 


$$
\begin{aligned}
\% \triangle P A G E S= & \alpha+\beta_{S} S H O C K+\beta_{E} B E T A_{-} P R E+ \\
& \delta_{1} S I Z E+\delta_{2} R O A+\delta_{3} D E R A T I O+\delta_{4} M B+\delta_{5} P P E+\varepsilon_{P G S}
\end{aligned}
$$

We estimate the model including either the initial shock (INIT_SHOCK) or the remaining shock (REM_SHOCK). Based on Section 2, we predict a positive association between the initial shock or the remaining shock and the percent change in pages. ${ }^{15}$

We include the pre-event beta (BETA_PRE) to account for the possibility that firms with higher pre-period systematic risk are simply more responsive. In addition, we include control variables for commonly cited determinants of disclosure such as firm size, performance, leverage and financing needs (Lang and Lundholm, 2000; Leuz and Wysocki, 2008). The proxies for these constructs are the natural log of total assets at December 31, 2000 (LASSETS $\left._{2000}\right)$; return of operating income on average assets for the year ended December 31, $2000\left(\mathrm{ROA}_{2000}\right)$; the debt-equity ratio at December 31,2000, which is the book value of long-term debt scaled by the market value of equity plus the book value of long-term debt and preferred shares $\left(\right.$ DERATIO $\left._{2000}\right)$; the market-book ratio at December 31, $2000\left(\mathrm{MB}_{2000}\right)$ where observations with a negative book value of equity are set to missing; and the ratio of property, plant and equipment, net, to total assets $\left(\mathrm{PPE} / \mathrm{TA}_{2000}\right)$ as a proxy for capital intensity. An extended model also includes changes in several of these variables from 2000 to 2001. All models include industryfixed effects based on one-digit SIC codes and a separate indicator variable for firms in Enronrelated industries (defined as SIC2 equal to 13, 29 or 49).

Table 3, Panel A presents results for eight model specifications. As the Enron shock is likely to affect firms in an industry similarly, our inferences are based on standard errors that are

\footnotetext{
${ }^{15}$ The relation between the initial shock and 10-K disclosure changes may be attenuated if firms address the shocks in the interim. This issue, which does not arise for the remaining shock, is discussed in more detail in Section 5.
} 
clustered at the two-digit SIC level. ${ }^{16}$ The results for models (1) - (4), which include the initial shock variable and four variations of control variables, show a positive and significant relation between the initial shock (INIT_SHOCK) and the percentage change in the page count of the 10K. The results for models (5) - (8), which include the remaining shock variable and four variations of control variables, show that the relation between the remaining shock (REM_SHOCK) and page count changes also is significantly positive. These results are robust to alternative sets of control variables. In particular, the results are similar and the inferences the same if we use the market value in computing firm size, employ contemporaneous, rather than lagged controls, and include only changes in the control variables in the model.

The positive associations for the initial and remaining shock with the disclosure changes in the 10-K are consistent with our hypotheses and the notion that firms' disclosures reduce their cost of capital. Although we do not make ex-ante predictions about the control variables, the results are consistent across all eight models and accord with our intuition. Firms with higher pre-event period betas, deteriorating operating performance, and with greater and growing firm size increase their 10-K disclosures more.

Standard computations of the marginal effect of the cost of capital shock on 10-K page changes from Models 2 and 4 suggest that an initial shock (or remaining shock) equal to the inter-quartile range of the pre-event beta is associated with an increase in 1.2 pages, which is $2 \%$ of the median number of $10-\mathrm{K}$ pages. While this effect may appear small, we emphasize that judging the increase against the total number of pages may not be appropriate because the $10-\mathrm{K}$ contains many pages that are boilerplate and hence uninformative. Thus, a $2 \%$ increase in the page count could represent a substantial increase in relevant information to investors. In fact, as

\footnotetext{
${ }^{16}$ Alternatively, we cluster our standard errors by auditor and obtain very similar inferences.
} 
a percentage, the page increase is much larger if we gauge it against key (or relevant) subsections of the 10-K (e.g., DISCUSS $2001, \mathrm{FS}_{2001}$ in Table 1) or compute the marginal effect for key subsections (e.g., $\% \Delta \mathrm{FS}$ in Table 3, Panel B). Moreover, the beta shocks are likely to be quite noisy, which could substantially attenuate the coefficient magnitudes. To gauge the effect of measurement error on the coefficients, we follow common practice and run reverse regressions, essentially switching the independent and dependent variables. These regressions (not tabulated) suggest that a $10 \%$ change in beta alone could explain the average page change in our sample. Thus, there are several pieces of evidence suggesting that the disclosure changes we observe are economically significant. ${ }^{17}$

We next analyze the determinants of page count increases in specific sections of the $10-\mathrm{K}$ that are likely to contain important relevant disclosures: $\% \Delta \mathrm{MDA}, \% \Delta \mathrm{FS}, \% \Delta \mathrm{DISCUSS}$ and $\% \triangle$ REL_PAR (see Section 3.3 for details). Table 3, Panel B, presents the results for models of these four disclosure change variables on the initial shock (INIT_SHOCK) or the remaining shock (REM_SHOCK) and the levels of the same control variables and industry dummies as in Panel A (Model 2). ${ }^{18}$ We find that the initial shock is positively associated with the page count changes for all four disclosure variables but the relation is statistically significantly for $\% \Delta \mathrm{FS}$ only. However, the coefficients are still fairly close to the coefficient on the initial shock in Panel A (Model 2) and, for $\% \Delta \mathrm{MDA}$ and $\% \Delta \mathrm{DISCUSS}$, the $\mathrm{p}$-values of the coefficients are close to conventional significance levels, suggesting that the reduced sample size and lack of power account for the drop in significance. The remaining shock is significantly associated with three of the four disclosure changes, i.e., $\% \Delta \mathrm{FS}, \% \Delta \mathrm{DISCUSS}$ and $\% \Delta \mathrm{REL} \_\mathrm{PAR}$.

\footnotetext{
${ }^{17}$ In addition, we document in Section 6 that firms' disclosure changes are associated with economically significant beta declines (and also abnormal volume reactions around the 10-K filings).

${ }^{18}$ The results are similar but stronger when we use model 1 and weaker but consistent when we include changes in the control variables (model 3).
} 
Next, we estimate the same models as in Table 3 using the percentage change in the word count of the earnings announcement in 2001 relative to 2000 (\% $\%$ WORDS) as our disclosure response variable. In these regressions, the cost of capital shocks do not exhibit a positive relation, are generally insignificant and the p-values are often far from conventional significance levels. For brevity, we do not tabulate these results. We subject the word count proxy to numerous refinements, e.g., we adjust the word counts for the occurrence of unusual corporate events and by industry; we convert the percentage changes into a simple variable indicating increases, decreases and approximately no change in the size of the earnings announcement; we focus on large changes only, drop small earnings announcements ( $<500$ words), and use log changes. These refinements do not change the conclusion that the shocks do not exhibit a positive association. Thus, it does not appear that noise in the earnings announcement proxy generates this (non-)result. While we are cautious about interpreting this finding, it is possible that earnings announcements are simply not well suited to address the transparency concerns that arose from the Enron collapse. They tend to be rather brief and they are not audited or subject to the same enforcement as official SEC filings. Another (but more minor) issue is that firms' earnings announcements and our pre-report beta estimation may overlap, which could result in confounding effects.

\subsection{Robustness tests}

We subject the results in the previous section to a large battery of robustness tests to address a number of potential concerns. First, in an effort to rule out spurious correlations as an explanation for the results, we examine whether the initial shock and remaining shock variables have any explanatory power for the percent change in page counts from 1999 to 2000 . They do not; the coefficients of interest in these "placebo" regressions are close to zero, as they should be. 
Second, in Panel C of Table 3, we address a number of concerns about the use of betas to measure cost of capital shocks. For brevity, we report only the key coefficients of interest, but the models include the full set of control variables from Models 2 and 6 in Panel A. In the first model, we use beta shocks derived from a linear market model. While quadratic beta estimates over the event period are conceptually preferred and better suited for our setting (e.g., to capture interim responses), we obtain similar results using linear beta estimates, which is reassuring. ${ }^{19}$

Another potential concern is that beta estimates for infrequently traded stocks are downward biased (Scholes and Williams, 1977). As a result, the estimated beta shocks may in part reflect differences in liquidity, which matters because liquidity and corporate disclosure are known to be related (e.g., Welker, 1995; Healy et al., 1999; Leuz and Verrecchia, 2000). To address this potential issue, we examine the relation between \% $\mathrm{PAGES}$ and the two beta shocks for the subsample of stocks with a share price above $\$ 5$ as they are less likely to have non-synchronous returns. As reported in Panel $\mathrm{C}$, the $\$ 5$ restriction reduces the sample size to 1,387 observations, but the results are very similar and the inferences are the same (see Model 2). The results are also robust to controlling for the log of average daily volume as a proxy for the downward bias in the beta estimates (not tabulated). ${ }^{20}$

Next, we address the concern that changes in the market's expectations about future cash flows as a result of the Enron scandal or the September 11 terrorist attacks unduly affect our findings. By using changes in beta, rather than abnormal returns, we should in principle separate cost of capital changes and updated assessments of future cash flows. Furthermore, our primary

\footnotetext{
${ }^{19}$ See Kumar et al. (2008) for a similar analysis of pre- and post-event betas using a linear market model.

${ }^{20}$ Another way to gauge the issue is to analyze the correlation between the residuals from the switching regime model and volume. This analysis (untabulated) reveals that the correlation is on average small, approximately 5-6\%, with approximately $20-30 \%$ of the correlations being significant and positive and $5-15 \%$ of the correlations being significant and negative. The correlations are similar across the pre-event, event, and pre-report periods.
} 
sample excludes firms that potentially had severe cash flow shocks due to the September 11 terrorist attacks. Nevertheless, we include the revision in the analysts' consensus forecast for next year's earnings, computed from August 2001 to December 2001, as a proxy for changes in cash flow expectations. The coefficient estimate on this variable is significantly negative, indicating that firms with larger downward revisions provide more disclosures. However, controlling for the forecast revisions does not alter our inferences for the beta shocks and, more importantly, including this proxy for changes in cash flow expectations does not attenuate the coefficients on INIT_SHOCK and REM_SHOCK as it would if our results were primarily driven by changes in cash flow expectations. ${ }^{21}$

Model 4 in Panel $\mathrm{C}$ includes a control variable for idiosyncratic return volatility to address the concern that (a) the quadratic beta model insufficiently separates systematic and idiosyncratic components of risk and (b) that stocks with higher volatility are simply also more responsive in their disclosures. We measure idiosyncratic volatility as the standard deviation of the residual from a linear market model over the pre-event period. The results are similar and the inferences the same if we use raw volatility over the pre-event period or idiosyncratic volatility over the event period as controls.

We also perform several robustness checks related to specific variable definitions (results not tabulated). First, we adjust the changes in page count and word count for the existence of events that may reflect a fundamental change in the firm's operations during the period that is correlated with both its beta and its required disclosures. For example, discontinued operations may be associated with changes in systematic risk and it is likely to be associated with changes in page counts given the SEC disclosure requirements associated with discontinued operations.

\footnotetext{
${ }^{21}$ This result also holds if we use the two-year ahead consensus forecast revision, rather than next year's revision. Simply controlling for analyst following does not alter our findings or inferences either.
} 
Our reviews of financial statements as well as SEC disclosure requirements suggest that the existence of the following irregular items (IRREGITEM) in the current year and two previous years can affect the length of the financial statements: discontinued operations, new segments, extraordinary items, accounting changes, certain special items (specifically litigation reserves or restructuring charges), and acquisition activity. We create seven indicator variables equal to one if the firm has evidence of these events based on Compustat data for the three years 1999, 2000, and 2001. We regress the changes in the page count on these indicator variables and use the residuals from the following model (firm subscripts omitted) as dependent variable in our regressions in Table 3, Panel A:

$$
\% \triangle P A G E S=d+\sum_{y=1999}^{2001} \sum_{j=1}^{7} k_{j y} \text { IRREGITEM }_{j y}
$$

While these adjustments provide a useful sensitivity check, it is a priori not obvious that the adjusted proxies dominate the unadjusted page (or word) changes. The transparency concerns after Enron and the cost of capital shocks may have induced firms to make decisions that would result in such items. For instance, "coming clean" on certain transactions is likely to result in extraordinary or special items. Nevertheless, our results are unaffected by these adjustments. That is, the positive association between the cost of capital shocks and the page changes continues to be significant and, more importantly, the coefficients of key interest are not materially altered, indicating that unusual corporate events and fundamental changes in the firm are not responsible for our findings.

Finally, we include controls for past performance, specifically for past losses as they may trigger additional language in firms' earnings announcements and 10-K filings (Li, 2008). Models (2) and (6) already include both $\mathrm{ROA}_{2000}$ and other models in Panel A of Table 3 include 
the change in ROA from 2000 to 2001. But given that operating performance generally lags stock returns, we expand these models to include the cumulative stock return over the pre-event period, the event or the pre-report period. In addition, we include an indicator variable for loss firms (in 2001 and, alternatively, 2000). The results are robust to the inclusion of these variables and the inferences remain the same.

\subsection{Cross-sectional analysis of the 10-K responses}

In this section, we present a cross-sectional analysis of firms' 10-K responses. As noted previously, we predict cross-sectional variation in the expected benefits to expanding the 10-K disclosures, which should lead to cross-sectional variation in firms' disclosure responses. Exploiting this cross-sectional heterogeneity should improve identification and increase the confidence in our earlier findings.

We argue in Section 2 that we expect the strongest disclosure response for firms that have high external financing needs and larger growth opportunities. These firms are more likely to be sensitive to shocks to their cost of capital as they are expected to be more frequently accessing capital markets. We also expect firms with positive shocks to respond more strongly, as the cost savings to decreasing disclosure may be small, and disclosure decreases may in fact increase expected litigation costs.

Therefore, we estimate our main page change model separately for firms with positive shocks and a high sensitivity to cost of capital shocks vs. the (residual) sample of firms that have either a negative shock or low financing needs. This specification allows the control variables to vary across subsamples and hence is more general than an interaction term. We use two proxies to identify firms that are more likely to be sensitive to cost of capital shocks because they have high financing needs: 1) Firms with an above-median investment cash flow during fiscal 2001 
scaled by total assets, and 2) firms with an above-median difference between the average growth rate over two years and the maximum growth rate that can be financed by internal funds. Following Demirgüc-Kunt and Maksimovic (1998), we compute the maximum internallyfinanced growth as ROA/(1-ROA). We consider alternative partitioning variables for firms' financing needs and growth opportunities, e.g., splitting by the market-to-book ratio, and obtain similar results. There are 946 (820) observations with a positive initial (remaining) shock and $922(1,048)$ observations with a negative one. We do not have data for the financing needs variables for all firms and hence have fewer observations than in Table 3. All models include the same control variables as specifications (2) and (6) in Table 3. The coefficients for the control variables are not presented to conserve table space.

Table 4, Panel A presents the cross-sectional results for \% $\mathrm{APAGES}$. Columns (1) through (4) present results using above-median investment cash flow to identify firms that are more sensitive to positive cost of capital shocks. Columns (5) through (8) present results using above-median external financing needs to identify high-sensitivity firms. The coefficient estimates on INIT_SHOCK in models (1), (2) and (6) are significant at the 10\% level or better. The coefficient estimate on REM_SHOCK is significant in model (7). More importantly, the coefficients on the shock variables, INIT_SHOCK and REM_SHOCK, for the group with positive shocks and high financing needs are much larger in magnitude than either the coefficients for the residual group or the coefficients on the shocks in Panel A of Table 3. We test whether the differences in the coefficients on the shocks are statistically significant across the two subsamples and can reject the null hypothesis for models (7) and (8). For models (1) and (2), the p-value is close to conventional significance levels (0.14), especially when considering that we cluster our standard errors at the industry level and hence draw conservative inferences. 
In Panel B, we report the same model specifications for the page changes in the MD\&A. We observe the same patterns for the coefficients on $\% \Delta \mathrm{MDA}$ as for the $10-\mathrm{K}$ page changes. That is, the estimated coefficient on $\% \Delta \mathrm{MDA}$ for firms with positive shocks and high financing needs exceeds the respective coefficient for the residual group in all cases. With the exception of the first model, the shock coefficients and their differences are not statistically significant but their magnitudes far exceed those in Panel B of Table 3, suggesting that the small sample size and hence lack of power are primarily responsible for the low t-statistics.

On November 29, 2001, the SEC expanded its investigation to include Enron's auditor, Arthur Andersen LLP (AA). The audit firm was indicted for obstruction of justice in 2002 and eventually went out of business as a result of the Enron collapse. We predict that AA clients are more likely to experience shocks to their cost of capital because of concerns over AA's credibility and hence are more likely to respond by increasing their disclosure. ${ }^{22}$ Consistent with this expectation, Panel $\mathrm{C}$ shows that AA clients exhibit larger coefficients on the initial shock using $\% \triangle \mathrm{PAGES}, \% \Delta \mathrm{MDA}$ and $\% \Delta \mathrm{REL} \_\mathrm{PAR}$. The difference in the coefficients between AA clients and non-AA clients is statistically significant for the $10-\mathrm{K}$ page changes and the related party disclosure changes.

In a final set of cross-sectional tests (untabulated), we drop the beta shocks and the preevent beta from the models in Panel A of Table 4 and re-estimate the page change models splitting the sample into firms with high and low financing needs. We then compare the constants across the subsamples. The idea behind this analysis is to test whether firms that ex ante are predicted to be more affected by the Enron shock do in fact increase their disclosures

\footnotetext{
${ }^{22}$ As discussed in Ball (2009), the Enron scandal was a more severe blow to the credibility of AA audit clients than prior financial reporting scandals had been for other audit firms because AA's reputation was already tarnished by prior scandals including Waste Management and Sunbeam, and because there were allegations that the Enron audit deficiencies involved top level management at AA and not just individuals.
} 
more than other firms. This analysis does not rely on the beta shocks and is merely built on the premise that the Enron scandal posed an exogenous transparency shock. We find that firms with larger financing needs, as measured by the same proxies as in Panel A, exhibit significantly larger disclosure increases, which supports our inferences.

\section{Analysis of the role of interim disclosures}

In this section, we analyze the relation between the cost of capital shocks and firms' interim disclosure responses. First, we include proxies for firms' interim disclosures as controls in our $10-\mathrm{K}$ page changes regressions. We use changes in 8-K filings, conference call activity, the length of the earnings announcement as well as a summary measure of the firm's response to the Enron shock derived from the regime switching model, i.e., the parameter estimate for $\hat{b}_{i 2}$. If interim disclosures and 10-K filings are complements, we expect a positive relation between the interim disclosure and the $10-\mathrm{K}$ page changes. Moreover, introducing the interim disclosures should strengthen the relation between the remaining shock and the $10-\mathrm{K}$ page response if the two disclosures are complements because the decline in beta due to the interim disclosure occurs with the expectation that firms still respond at the $10-\mathrm{K}$. Thus, controlling for the interim disclosures should help the relation between REM_SHOCK and \% $\triangle$ PAGES.

We expand Models (2) and (6) from Table 3 to include proxies for the four interim disclosure proxies. Table 5 reports the results from these regressions. Models (1) and (2) include $\triangle 8 \mathrm{KCOUNT}$ and Models (3) and (4) include $\triangle \mathrm{CALL}$. The coefficient estimates on INIT_SHOCK and REM_SHOCK are comparable to Table 3 and remain significant in both cases. The change in the number of 8-K filings is positively associated with the percentage change in $10-\mathrm{K}$ pages. The association between the change in the number of conference calls and the change in the 10-K page counts is negative but not significant. Models (5) and (6) 
include the percent change in word count in the annual earnings announcement $(\% \Delta$ WORDS). The association between this change and the change in the 10-K page count is positive but again not significant. This result is consistent with our earlier analyses relating changes in firms' earnings announcements to the beta shocks and suggests that changes in earnings announcements are not suited to address investors' transparency concerns as a result of the Enron collapse.

Model (7) includes the $\hat{b}_{i 2}$ parameter from the regime-switching model as a proxy for firms' immediate responses to the initial shock and, hence, we estimate this model for the remaining shock only. As illustrated in Figure 1, $\hat{b}_{i 2}$ captures the direction of the beta shock and the curvature of quadratic event beta. One explanation for this curvature is that a firm has responded to the initial shock, for example, through interim disclosures or other actions that enhance a firm's credibility, such as a change in dividend policy. In this sense, $\hat{b}_{i 2}$ is a summary measure of a firm's responses to the initial shock and should capture the effects of all actions the firm takes during the event period, regardless of whether we can separately identify or measure them. The downside of this measure, however, is that $\hat{b}_{i 2}$ may also capture changes in the cost of capital unrelated to a firm's actions, including recoveries in the cost of capital due to information transfers from other firms. However, as long as these other changes are not systematically biased, they should introduce only noise into our analysis.

The percent change in 10-K pages has a positive and significant association with $\hat{b}_{i 2}$, indicating that there are complementarities between a firm's immediate responses to the shock and the disclosure response in the $10-\mathrm{K}$ filing. Moreover, including $\hat{b}_{i 2}$ significantly increases the coefficient on REM_SHOCK (using a Chow test), which is expected if interim responses and the $10-\mathrm{K}$ are complements. 
Next, we directly examine the relation between firms' interim disclosure responses and the cost of capital shocks. Table 6 is the analog to the analysis of the 10-K responses in Table 3 using the two immediate disclosure responses as dependent variables. Model (1) in Table 6 shows that the association between changes in firms' 8 -K filings and the initial shock is positive and significant, suggesting that firms respond to the shock with the release of 8-K filings. As the measurement of the change in $8-\mathrm{K}$ filings and the event period overlap, we re-run the model measuring the change in 8-K filings starting in the middle of the event period (i.e., November 8), so that the shock is measured largely before the disclosure response. Again, the association between the shock and the 8-K response is positive and significant. Next, to see whether the additional 8-K filings help mitigate the cost of capital shocks, we restrict the change in 8-K filings to those that occur over the second-half of the event period, i.e., after the peak of the event period beta and up to the start of the pre-event period (i.e., December 6, 2001). Model (2) shows that the coefficient on REM_SHOCK is negative and significant, consistent with the idea that immediate 8-K responses mitigate the initial shock. ${ }^{23}$

Models (3) and (4) perform the same tests for the change in the number of conference calls. We do not find a positive association with the initial shock, but the coefficient on the remaining shock is negative and close to conventional significance levels ( $\mathrm{p}=0.185$, two-sided), which is consistent with the results for the 8-K findings. Moreover, the latter association is significantly negative at the $1 \%$ level if we use changes in the conference calls over the entire event window, i.e., from October 15 to December 6, 2001. ${ }^{24}$

\footnotetext{
${ }^{23} \mathrm{We}$ also confirm that the decline in the beta from the event period peak to the pre-report beta is significantly related to the change in 8-K filings.

${ }^{24} \mathrm{We}$ also estimate seemingly unrelated regressions using both interim disclosure variables simultaneously to account for dependencies among them and obtain the same inferences.
} 
Models (5) and (6) estimate the relation between the interim disclosure responses and the

$\hat{b}_{i 2}$ parameter from the regime switching model to see whether the curvature in the quadratic event beta is indeed related to firms' interim responses. Models (5) and (6) show a positive association for both interim disclosures, consistent with the idea that the curvature reflects among other things firms' immediate responses, but the relation is significant only for the additional 8-K filings. The weaker findings for the conference calls could stem from the fact that they are purely voluntary and not subject to SEC review.

Taken together, the results in Tables 5 and 6 suggest that some firms respond immediately to the cost of capital shocks and that these interim responses are complements to 10-K disclosures. The results also highlight that using a quadratic beta estimate during the event period is an important feature of our analysis. We intentionally define the event period to be long enough to capture the series of Enron-related events that led to the transparency crisis. However, an extended event period increases the likelihood of confounding events, in particular, due to firms' responses to the initial shock. Our regime-switching model addresses this issue by being flexible enough to capture these interim responses in the beta estimation.

\section{Analysis of market reactions to $10-\mathrm{K}$ filings}

In our final set of analyses, we examine whether firms' disclosure changes have subsequent market reactions and whether they address mitigate the cost of capital shocks. Finding such reactions would corroborate the results for firms' interim disclosures in Table 6 and address the concern that firms simply increase disclosures to reduce litigation risk or to thwart future regulation but do not provide information that is useful to investors. In relating changes in disclosure to subsequent changes in the cost of capital, the tests in this section are similar to 
those in traditional disclosure studies, except that the disclosure changes in our study are induced by an exogenous information-related shock.

We analyze both post 10-K filing changes in systematic risk and short-window abnormal volume responses to the $10-\mathrm{K}$ filing. We begin with the beta response. We define the beta response (BRESPONSE) as the change in systematic risk from the event period to the post-filing period. We estimate the post-filing period beta (BETA_POST) after the annual report season from May 1, 2002 to August 31, 2002 using a standard market model. Thus, BRESPONSE = BETA_EVT - BETA_POST. A positive value of the beta response variable suggests a greater recovery of the beta relative to the peak level of systematic risk during the event period. We are able to estimate BRESPONSE for 1,797 observations.

The measure of abnormal volume is a firm-specific measure (Asthana et al., 2004) that has been applied specifically in the context of $10-\mathrm{K}$ filings. We define abnormal volume $\left(A B N \_V O L_{t}^{i}\right)$ for firm $i$ on day $t$ as:

$$
A B N_{-} V O L_{t}^{i}=\frac{V O L_{t}^{i}-\mu^{i}\left(V O L_{d}^{i}\right)}{\sigma^{i}\left(V O L_{d}^{i}\right)}
$$

where $V O L_{t}^{i}$ represents daily trading volume for firm $i$ on day $t$. Consistent with Asthana et al. (2004), we define the non-filing period as the 45-day window from 49 days before to five days before the $10-\mathrm{K}$ filing date. We measure the mean $(\mu)$ and standard deviation $(\sigma)$ of daily trading volume for each firm $i$ over this non-filing period and compute abnormal volume for a five-day event window around the $10-\mathrm{K}$ filing date $(-1,+3)$.

Table 7, Panel A presents the analysis for the beta response using various combinations of control variables. We use firm characteristics that are usually related to the cost of capital, 
such as size, the market-to-book ratio and leverage as controls (in both levels and changes). We find that the percentage change in the $10-\mathrm{K}$ page is significantly related to the decline in beta for all three models. Gauging the magnitude of the effects suggests that the mean page increase is associated with a $5 \%$ decline in beta. These findings are consistent with the interpretation that the 10-K disclosure responses are useful to investors and alleviate the beta shocks.

Table 7, Panel B presents the analysis of abnormal volume. The models include control variables consistent with Asthani et al. (2004). In particular, we control for last year's abnormal volume response to the $10-\mathrm{K}$ to ensure that any effect for $\% \triangle \mathrm{PAGES}$ stems indeed from the increase in pages and not a cross-sectional difference in firms' volume responses to the $10-\mathrm{K}$. Furthermore, we include a control variable capturing the delay in the filing of the $10-\mathrm{K}$, which Asthana et al. (2004) document as being related to the abnormal volume response. We find that the $\% \triangle$ PAGES is significantly related to the abnormal volume reaction in all three models. This finding is consistent with the interpretation that the additional disclosures in the $10-\mathrm{K}$ are informative to investors and hence lead to greater turnover at the filing of the 10-K.

\section{Conclusions}

In this paper, we analyze the relation between disclosure and the cost of capital using an exogenous, information-related cost of capital shock created by the Enron scandal in Fall 2001. We begin with tests that have the opposite structure of the typical research design. In reversing the tests and using an exogenous shock, we mitigate endogeneity concerns in traditional crosssectional disclosure studies, especially with respect to omitted factors that jointly determine firms' disclosure choices and their cost of capital. Our analysis is based on an event-study technique that allows us to estimate shocks to firms' betas as well as accommodate subsequent changes in beta due to firms' interim responses to the transparency crisis. 
Our analysis shows that beta shocks around the Enron scandal are associated with increased disclosure. Firms expand the number of pages of their annual 10-K filings, notably the sections containing the narrative disclosures like the MD\&A and related-party transactions as well as the financial statements and footnotes. The increase in disclosure is particularly pronounced for firms that have positive cost of capital shocks and larger financing needs and for firms that have larger credibility issues. We also find that firms respond with additional interim disclosures (e.g., 8-K filings), which have an immediate impact on the firm's cost of capital. We document that the $10-\mathrm{K}$ disclosures are complementary to the interim disclosures; firms provide them even though the interim disclosures already reduce the beta shock. Finally, we show that firms' $10-\mathrm{K}$ disclosure responses have significant subsequent market reactions (e.g., abnormal volume) and are effective in reducing the cost of capital shocks.

These results complement prior disclosure studies by explicitly linking informationrelated cost of capital shocks to firms' disclosure responses. In doing so, we increase the empirical support for the fundamental link between disclosure and firms' cost of capital. Our study also provides novel evidence that firms respond to shocks to the credibility of their financial reports. This evidence is important as it shows that firms can mitigate the impact of a wider transparency crisis and that firm-specific disclosures can influence the cost of capital. We emphasize, however, that this result should not be used to justify additional disclosure requirements as firms that voluntarily responded more to the cost of capital shock were those with the greatest hypothesized benefits. 


\section{Appendix}

Section A.1 describes Enron-related events between October 16, 2001 and January 26, 2002. From these, we identify seven potential sets of pre-event - event - pre-report windows that are outlined in Section A.2. The final section of the Appendix reports the results of an $e x$ post analysis of the beta estimates over the various windows to assess their validity.

\section{A.1 Event dates related to Enron}

We identify potentially significant events from published timelines of the Enron scandal (e.g., Platts, 2002; Washington Post, 2002), and from independent searches of news reports. Potentially important event dates in the context of our study are those that changed investors' prior beliefs about the likelihood or magnitude of private information about the sample firm.

We identify three types of event dates. First, we identify six Enron-specific events that are also indicators that financial reporting or corporate governance problems may be widespread.

Oct. 16: Enron first announces its huge losses and hints of conflict-of-interest problems with its partnerships.

Oct.22: Enron announces that the SEC has launched an inquiry.

Oct 29: The SEC moves its inquiry to DC signaling a higher likelihood of securities violations. Oct 31: The SEC initiates a formal investigation.

Nov 8: Enron restates earnings back to 1997.

Nov 29: The SEC's investigation is expanded to include Arthur Andersen LLP.

These events are specific to Enron, but they are not necessarily the most significant for Enron based on an analysis of its stock returns. This set does not include events such as a credit rating downgrade of Enron's debt or a takeover offer of Enron which are significant for Enron but unlikely (in our view) to have broad implications for information problems at other firms.

Second, we identify events that directly indicate that the information problems at Enron are expected to be systemic. 
Nov 19: Representative John Dingell requests that the Public Oversight Board (POB) review Andersen's audits of Enron

Nov 29: SEC Chairman Harvey Pitt calls pro forma earnings "unstructured and undisciplined" and suggests that the SEC is focusing attention on misleading financial reporting.

Dec 4: The Big-five firms pledge to work together to address financial reporting problems.

Jan. 7: It is reported that the Big Five have petitioned the SEC to improve disclosure regulation.

Jan 9: $\quad$ The Senate Banking Committee, headed by Sen. Paul Sarbanes, announces its plans to hold a hearing Feb. 12 to examine accounting and investor protections. The US Justice Department's fraud section also announces that it will form a special task force to examine the collapse of Enron.

Third, we identify financial press discussions that suggest that the Enron scandal was not an isolated problem but rather an indicator of corporate transparency and corporate governance problems.

Nov 5: “What Enron's Financial Reports Did - and Didn't - Reveal --- Auditor Could Face Scrutiny on Clarity of Financial Reports" (Wall Street Journal, p. C1)

Nov 8: In a DJ Newswire column, the author speculates that Enron's partnership accounting problems, which resulted in significant earnings restatements, could push the FASB to prioritize its projects on SPEs from having standards of ownership including provisions for minimum ownership by unaffiliated outsiders to control-based standards. The article also questions Arthur Andersen's responsibilities given the restatements.

Nov 26: Business Week cover story is "CONFUSED ABOUT EARNINGS? You're not alone. Here's what companies should do--and what investors need to know."

Jan 26: "Trying not to be the next Enron, companies scrutinize practices" appears on p.1 of the New York Times Saturday business section.

These articles are not events per se. However, it is possible (or even likely) that the articles affected public opinion about the systemic nature of the transparency problem. Existing research has shown that articles in the financial press do affect investor opinions (e.g., Foster, 1979; Foster, 1987; Chang and Suk, 1998; Pruitt et al. 2000; Huberman and Regev, 2001). It is also possible that the articles reflect public opinion rather than create it, which is another reason to search for and consider these dates. We end our search for such articles in January 2001 because that is the start of the earnings announcement season. 


\section{A.2 Identification of event windows}

Figure A1 shows the value-weighted and equal-weighted index from August 1, 2001 through February 28, 2002 and provides some context for the window selection. The figure illustrates the high volatility period associated with the September $11^{\text {th }}$ terrorist attacks. The arrows point to the start dates and the end dates that we consider for the event period.

\section{Figure A1: Index returns}

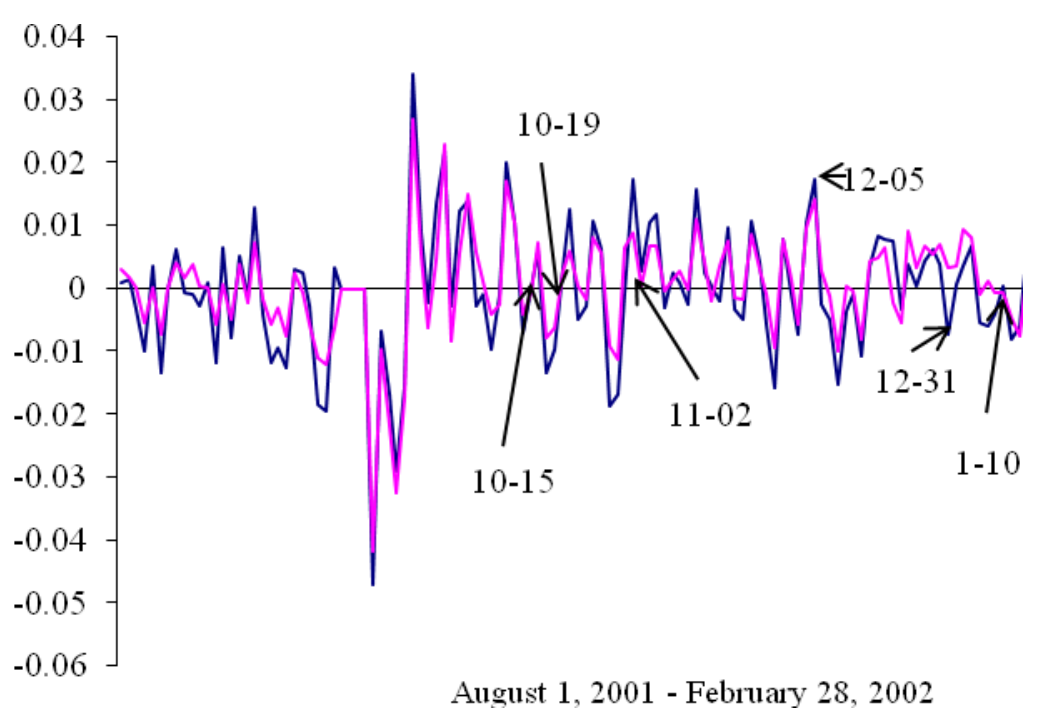

We identify seven combinations of windows to estimate systematic risk for the pre-event period (BETA_PRE), the event period (BETA_EVT), and the pre-report period (BETA_REM). In the timelines below, $\mathrm{T} 1$ and $\mathrm{T} 2$ define the endpoints of the event period. The center date of the event period is noted for each window. In all scenarios, the end of the pre-event period is August 31,2001 . There is a discontinuity between the end of the pre-event period and the beginning of the event period ranging from 44 to 62 days. The discontinuity allows us to avoid 
the week-long trading halt and subsequent high volatility period associated with September 11. In addition, the discontinuity is advantageous because the pre-event period is not contaminated when we do not properly identify the start of the event period. The discontinuity does not affect the estimation procedure.

\section{Alternative Windows for the Beta Estimation}

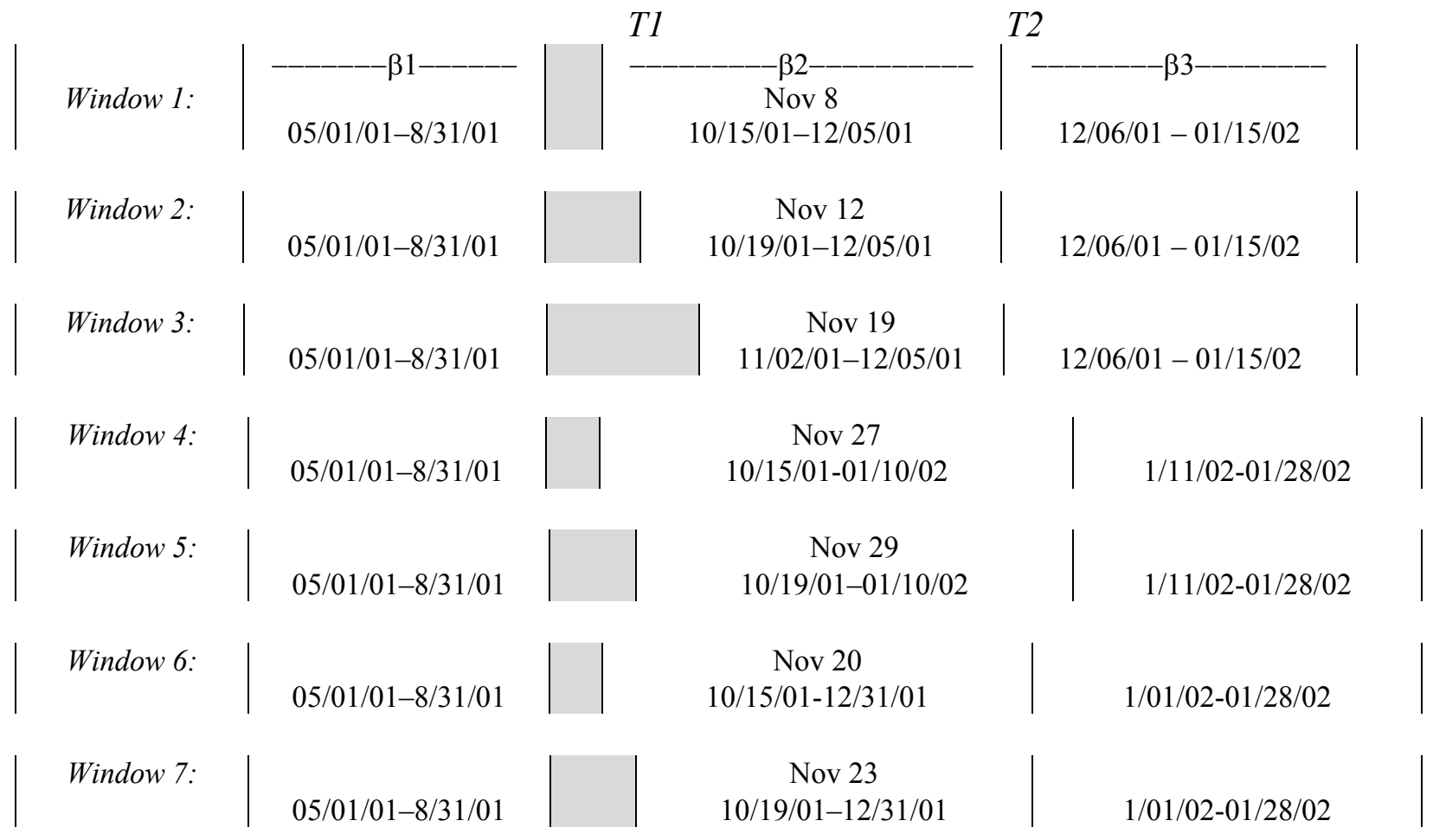

We consider three start dates for the event window: October 15, October 19, and November 2, 2001. October 15 is day t-1 relative to Enron's announcement that it lost $\$ 618$ million, which provided the first indication of possible conflict-of-interest questions related to the Fastow-run partnerships and the "quality" of Enron's prior-period earnings. October 19 is trading day t-1 relative to Enron's announcement of an SEC investigation of the partnerships and of suspicions by analysts that Enron will release additional bad news (October 22). November 2 is the start date that makes November 19 the center of the event window. November 19 is significant because on that day it is first reported that Representative John Dingell requested that 
the Public Oversight Board (POB) review Andersen's audits of Enron (and Waste Management).

The public oversight Board declines to review specific cases but indicates that it will consider a systemic review.

We consider two end dates for the event window. The end date in windows 1-3 is December 5 , which is day $\mathrm{t}+1$ relative to the pledge by the big-five firms to work together to address financial reporting problems, especially related to SPEs and market risks. The event periods in these windows include all of the Enron-specific events and all but three of the systemic and financial press events. The pre-report period begins December 6 and ends on January 15,2002 , which is the first percentile of fourth quarter earnings announcement dates.

In windows 4 and 5, the event period extends to January 10, 2002, which is day $\mathrm{t}+1$ relative to the last systemic event and it includes all but the last financial press event. Because of the longer event period, we are forced to extend the length of the pre-report period to January 28 in order to have a sufficiently long pre-report period to estimate the model. January 28 represents the first quartile of earnings announcement dates. In windows 6 and 7, we arbitrarily set the end of the event window at December 31, 2001. This specification provides more equally-sized windows for the event-period and the pre-report period.

\section{A.3 Analysis of beta estimates}

We use beta estimates from window $1 .^{25}$ In choosing among the windows, the primary trade-off is that a longer event window, which is more inclusive of important events,

\footnotetext{
${ }^{25}$ There is no ex-post diagnostic tool that establishes the best window. Lockwood and Kadiyala (1988) estimate the model for every combination of event windows with a start date within 30 days prior to the one day event (T1) and an end date within 30 days after the event (T2). The window (T1, T2 combination) that maximizes the log likelihood function is chosen as the best firm-specific model. However, they have firm-specific events whereas we have a common event to all firms.
} 
mechanically shortens the pre-report window given that the report date (either the earnings announcement date or the $10-\mathrm{K}$ date) is fixed.

Several analyses favor the shorter event periods (windows 1-3). The means (medians) of the adjusted $\mathrm{R}^{2} \mathrm{~s}$ from the model estimation are higher for these windows than for the other windows (although the differences are not significant). Windows 1-3 also produce the smallest number of negative $\hat{b}_{i 1}$ estimates (regardless of the start date). Finally, the residuals for windows 1,2 and 3 are mean zero during the pre-event period and the event period. They are significantly positive during the pre-report period (at approximately the $10 \%$ level). In windows $4-7$, the residuals during the event (pre-report) period are positive (negative) and significant. None of the analyses indicate a difference between windows 1-3. Thus, we report results for the window that allows the earliest possible start date, i.e., window 1.

The beta shocks estimated from window 1 have associations and exhibit cross-sectional variation that support their validity. For example, the median initial shock for the 45 firms that have Enron-related 8 -Ks is 0.21 , which is significantly greater than the median initial shock for the remaining 2,056 firms of 0.006 . The median remaining shocks also are greater $(0.18$ vs. 0.10), but the difference is not significant. The median initial shocks for the Arthur Andersen clients are not significantly different ( 0.04 for AA clients vs. 0.005 for non-AA clients), but the remaining shocks are significantly higher by 0.043 at the $10 \%$ level. This pattern is consistent with the fact that Arthur Andersen was not implicated in the scandal until later in the event window. There is a significant positive correlation between the initial shock and firm size (measured either by market capitalization or total assets) and leverage (measured by the debtequity ratio). There is a significant positive correlation between the remaining shock and firm size, leverage, and operating leverage (measured by the ratio of PPE/total assets), and a 
significant negative correlation between analyst following and the initial shock. This last result suggests that firms with ex ante better information environments have smaller shocks to the Enron-related transparency crisis. 


\section{References}

Amihud, Y. and H. Mendelson, 1986. The Effects of Beta, Bid-Ask Spread, Residual Risk and Size on Stock Returns. Journal of Finance, 479-486.

Asthana, S., S. Balsam, and S. Sankaraguruswamy, 2004, Differential Response of Small versus Large Investors to 10K Filings on Edgar, Accounting Review 79, 571-589.

Ball, R., 2009, Market and Political/Regulatory Perspectives on the Recent Accounting Scandals, Journal of Accounting Research 47, forthcoming.

Barry, C., and S. Brown, 1984, Differential Information and the Small Firm Effect, Journal of Financial Economics 13, 283-294.

Barry, C., and S. Brown, 1985, Differential Information and Security Market Equilibrium, Journal of Financial and Quantitative Analysis 20, 407-422.

Beneish, M., P. Hopkins, I. Jansen, and R. Martin, 2005, Do Auditor Resignations Reduce Uncertainty About the Quality of Firms' financial reporting?, Journal of Accounting and Public Policy 24, 357-390.

Botosan, C., 1997, Disclosure Level and the Cost of Equity Capital, The Accounting Review 72, 323-349.

Botosan, C., and M. Plumlee, 2002, A Re-Examination of Disclosure Level and the Expected Cost of Equity Capital, Journal of Accounting Research 40, 21-40.

Brown, S., 1979, The Effect of Estimation Risk on Capital Market Equilibrium, Journal of Financial and Quantitative Analysis 15, 215-220.

Carter, D., and B. Simkins, 2004, The Market's Reaction to the Unexpected, Catastrophic Events: The Case of Airline Stock Returns and the September 11th Attacks, Quarterly Review of Economics and Finance 44, 539-558.

Chang, S., and D. Suk, 1998, Stock Prices and the Secondary Dissemination of Information: The WSJ's Insider Trading Spotlight Column, Financial Review 33, 115-128.

Clarkson, P., and R. Thompson. 1990. Empirical Estimates of Beta When Investors Face Estimation Risk. Journal of Finance 45, 431-53.

Coles, J., and U. Loewenstein, 1988, Equilibrium Pricing and Portfolio Composition in the Presence of Uncertain Parameters and Estimation Risk, Journal of Financial Economics 22, 279-303.

Coles, J., U. Loewenstein, J. Suay, 1995, On equilibrium pricing under parameter uncertainty, The Journal of Financial and Quantitative Analysis 30, 347-374.

Cyree, K.,. and R. DeGennaro, 2002, A Generalized Method for Detecting Abnormal Returns and Changes in Systematic Risk, Review of Quantitative Finance and Accounting 19, 399416.

Demirguc-Kunt, A., and V. Maksimovic, 1998, Law, Finance, and Firm Growth, Journal of Finance, 2107-2137.

Diamond, D., and R. Verrecchia, 1991, Disclosure, Liquidity, and the Cost of Capital, Journal of Finance 46, 1325-1359. 
Doherty, N., J. Lamm-Tennant, and L. Starks, 2003, Insuring September 11th: Market Recovery and Transparency, Journal of Risk and Uncertainty 26, 179-199.

Easley, D., S. Hvidkjaer , and M. O'Hara , 2002, Is Information Risk a Determinant of Asset Returns?, Journal of Finance 57, 2185-2221.

Easley, D., and M. O'Hara, 2004, Information and the Cost of Capital, Journal of Finance, 59, 1553-1583.

Foster, G., 1979, Briloff and the capital market, Journal of Accounting Research 17, 262-274.

Foster, G., 1987, Rambo IX: Briloff and the capital market, Journal of Accounting, Auditing and Finance 2, 409-430.

Francis, J., LaFond, R., Olsson, P., and Schipper, K., 2004. Costs of Equity and Earnings Attributes. The Accounting Review 79, 967-1010.

Francis, J., LaFond, R., Olsson, P., and Schipper, K., 2005. The Market Pricing of Accruals Quality. Journal of Accounting and Economics 39, 295-327.

Garleanu, N., and L. Pedersen, 2004, Adverse Selection and the Required Return. Review of Financial Studies 17, 643-665.

Grullon, G., R. Michaely, and B. Swaminathan, 2002, Are Dividend Changes a Sign of Firm Maturity? Journal of Business 75, 387-424.

Handa, P., and S. Linn, 1993, Arbitrage Pricing with Estimation Risk. Journal of Financial and Quantitative Analysis, 28, 81-100.

Healy, P., A. Hutton, and K. Palepu, 1999, Stock Performance and Intermediation Changes Surrounding Sustained Increases in Disclosure, Contemporary Accounting Research 16, 485-520.

Huberman, G., and T. Regev, 2001, Contagious Speculation and a Cure for Cancer: A NonEvent that Made Stock Prices Soar, Journal of Finance, 56, 387-396.

Klein, R., and V. Bawa, 1976, The Effect of Estimation-Risk on Optimal Portfolio Choice, Journal of Financial Economics 3, 215-31.

Klein, R. and V. Bawa, 1977, Effect of limited information and estimation risk on optimal portfolio diversification, Journal of Financial Economics 5, 89-111.

Kumar, P., S. Sorescu, R. Boehme, and B. Danielsen, 2008, Estimation Risk, Information, and the Conditional CAPM: Theory and Evidence. Review of Financial Studies, 21, 1037-1075.

Lambert, R., C. Leuz, and R. Verrecchia, 2007, Accounting Information, Disclosure, and the Cost of Capital, Journal of Accounting Research 45, 385-420.

Lambert, R., and R. Verrecchia, 2008, Cost of Capital in Imperfect Competition Settings, Working Paper.

Lang, M. and R. Lundholm, 2000, Voluntary Disclosure and Equity Offerings: Reducing Information Asymmetry or Hyping the Stock?, Contemporary Accounting Research 17, 623.

Lettau, M. and S. Ludvigson, 2001, Resurrecting the (C)CAPM: A Cross-Sectional Test When Risk Premia Are Time-Varying, Journal of Political Economy 6, 1238-1287. 
Leuz, C., and R. Verrecchia, 2000, The Economic Consequences of Increased Disclosure, Journal of Accounting Research 38, 91-124.

Leuz, C., and P. Wysocki, 2008, Economic Consequences of Financial Reporting and Disclosure Regulation: A Review and Suggestions for Future Research, University of Chicago Working Paper.

Li, F., 2008, Annual report readability, current earnings, and earnings persistence, Journal of Accounting and Economics 45, 221-247.

Lockwood, L., and K. Kadiyala, 1988, Risk Measurement For Event-Dependent Security Returns, Journal of Business and Economic Statistics 6, 43-49.

Platts, 2002, The collapse of Enron: Timeline of events, www.platts.com.

Pruitt, S., B. Van Ness and R. Van Ness, 2000, Clientele Trading in Response to Published Information: Evidence from the 'Dartboard' Column, Journal of Financial Research 23, 1-13.

Reinganum, M., and J. Smith, 1983, Investor Preference for Large Firms: New Evidence on Economies of Size, Journal of Industrial Economics, Blackwell Publishing 32, 213-227.

Scholes M., and J. Williams, 1977, Estimating betas from nonsynchronous data, Journal of Financial Economics 5, 309-327.

Schrand, C., and R. Verrecchia, 2005, Information Disclosure and Adverse Selection Explanations for IPO Underpricing, Working paper, University of Pennsylvania.

Wang, K., 2003, Asset Pricing with Conditioning Information: A New Test, Journal of Finance $57,161-96$.

Washington Post, 2002, Timeline of Enron's Collapse, February 25, www.washingtonpost.com.

Welker, M., 1995, Disclosure Policy, Information Asymmetry, and Liquidity in Equity Markets, Contemporary Accounting Research 11, 801-827. 


\section{Table 1 \\ Descriptive statistics on disclosure proxies and firm characteristics}

The sample comprises a maximum of 1,868 firms with a December 31 fiscal year end and sufficient data to estimate subsequent models. We eliminate airlines, insurance carriers, and firms that are majorly affected by the September $11^{\text {th }}$ terrorist attacks. Panel A provides descriptive statistics for the disclosure proxies in our analyses. It presents counts of the number of pages for the entire $10-\mathrm{K}$ in 2001 ( PAGES $\left._{2001}\right)$; the management discussion and analysis $\left(\mathrm{MDA}_{2001}\right)$ section (Item 7); the sum of Items 6 (Selected Financial Data), 8 (Financial Statements and Supplementary Data), and 15 (Exhibits, Financial Statement Schedules, and Reports on Form 8-K), which commonly include financial tables $\left(\mathrm{FS}_{2001}\right)$; and the sum of Items 1 (Business), 2 (Properties), and 7 (MD\&A), which commonly include narrative discussions about the firm (DISCUSS 2001 ). We also present the percent changes $(\% \Delta)$ in these variables relative to the year 2000 . We select the disclosures on related-party transactions from the $10-\mathrm{K}$ or the proxy statement. REL_PAR 2001 is the number of pages of this section. $\% \triangle R E L \_P A R$ is the percentage change in these pages counts from 2000 to 2001, after setting changes of plus or minus one page to zero. WORDS $_{2001}$ is the word count for the fourth quarter and annual 2001 earnings announcement and \% $\Delta$ WORDS is the percent change in the word count relative to the prior year. The preceding change variables are truncated at the $1^{\text {st }}$ and $99^{\text {th }}$ percentile, except $\% \Delta$ PAGES, which is truncated at $2^{\text {nd }}$ and $98^{\text {th }}$ percentile. 8 KCOUNT is the number of 8 $\mathrm{K}$ filings between October 15, 2001 and March 31, 2002, but excluding filings related to the September $11^{\text {th }}$ terrorist attacks. $\triangle 8 \mathrm{KCOUNT}$ is the difference in the count over the same period in 2000 , winsorized at +3 and -3 . CONFCALL is the number of conference calls from October 15, 2001 to March 31, 2002. $\triangle$ CALL denotes the difference in the number of calls relative to the same period one year earlier, winsorized at +3 and -3 . $* * *(\dagger \dagger \dagger)$ and * $(\dagger)$ indicate that the mean (median) change in the respective variable is significantly different from zero at the $1 \%$ and $10 \%$ level, respectively.

Panel A: Disclosure proxies

\begin{tabular}{|c|c|c|c|c|c|c|}
\hline & $\mathrm{N}$ & Mean & Std dev & p25 & Median & p75 \\
\hline \multicolumn{7}{|l|}{ 10-K Page counts } \\
\hline PAGES $_{2001}$ & 1,868 & 63.619 & 29.720 & 44 & 62 & 79 \\
\hline $\mathrm{MDA}_{2001}$ & 1,116 & 13.320 & 8.574 & 7 & 11 & 18 \\
\hline DISCUSS $_{2001}$ & 1,163 & 26.693 & 13.793 & 17 & 25 & 34 \\
\hline $\mathrm{FS}_{2001}$ & 1,163 & 34.013 & 16.995 & 25 & 32 & 40 \\
\hline$\% \triangle$ PAGES & 1,868 & $16.6 \% * * *$ & $31.5 \%$ & $0.0 \%$ & $9.0 \% \dagger \dagger \dagger$ & $23.6 \%$ \\
\hline$\% \Delta \mathrm{MDA}$ & 1,116 & $38.7 \% * * *$ & $44.7 \%$ & $10.0 \%$ & $30.4 \% \dagger \dagger \dagger$ & $57.1 \%$ \\
\hline$\% \Delta$ DISCUSS & 1,158 & $22.2 \% * * *$ & $32.1 \%$ & $3.7 \%$ & $17.6 \%+\dagger \dagger$ & $35.0 \%$ \\
\hline$\% \Delta \mathrm{FS}$ & 1,145 & $17.6 \% * * *$ & $56.6 \%$ & $0.0 \%$ & $8.0 \% \dagger \dagger \dagger$ & $22.6 \%$ \\
\hline \multicolumn{7}{|l|}{ Proxy statement counts } \\
\hline REL_PAR 2001 & 1441 & 4.822 & 9.003 & 0 & 1 & 4 \\
\hline$\% \triangle \overline{R E L}_{-} \mathrm{PAR}$ & 1312 & $19.4 \% * * *$ & $99.5 \%$ & 0 & 0 & 0 \\
\hline \multicolumn{7}{|l|}{ EA Word counts } \\
\hline WORDS $_{2001}$ & 1,788 & 2,003 & 1,262 & 1,197 & 1,706 & 2,446 \\
\hline$\% \triangle \mathrm{WORDS}$ & 1,715 & $15.5 \% * * *$ & $32.2 \%$ & $-5.1 \%$ & $9.0 \%+\dagger \dagger$ & $28.9 \%$ \\
\hline \multicolumn{7}{|l|}{$8-K$ counts } \\
\hline 8KCOUNT & 1,868 & 0.904 & 1.771 & 0 & 0 & 1 \\
\hline (without Sept 11) & 1,868 & 0.760 & 1.568 & 0 & 0 & 1 \\
\hline$\Delta 8 \mathrm{KCOUNT}$ & 1,868 & $0.052^{*}$ & 1.220 & 0 & 0 & 0 \\
\hline (without Sept 11) & 1,868 & 0.004 & 1.159 & 0 & 0 & 0 \\
\hline \multicolumn{7}{|l|}{ Conference Call } \\
\hline CONFCALL & 1,868 & 1.140 & 0.955 & 0 & 1 & 2 \\
\hline$\triangle \mathrm{CALL}$ & 1,868 & $-0.074 * * *$ & 0.642 & 0 & 0 & 0 \\
\hline
\end{tabular}




\section{Table 1 (continued) Descriptive statistics on disclosure proxies and firm characteristics}

Panel B provides descriptive statistics on firm characteristics that we use as control variables in subsequent models. TOTASS is the book value of total assets (in millions). SIZE is the market value of common equity plus the book value of preferred stock and long-term debt (in millions). ROA is return on assets using the operating income after depreciation and amortization and scaling it by the average of total assets at the beginning and the end of the fiscal year. CUMRET is the cumulative return from May 1, 2001 to August 31, 2001. DERATIO is long-term debt scaled by total assets at the end of the fiscal year. MB is the market-to-book ratio of common shareholders' equity, setting the ratio to zero for book value $<0$. PPE/TA is the book value of net property, plant and equipment scaled by total assets. FCSTREV is the change in the mean (consensus) analyst forecast of next-fiscal-year annual earnings during the period from August 2001 to December 2001 scaled by price. FIRMRETVOL is the firm's idiosyncratic risk during the pre-event period, where idiosyncratic risk is the standard deviation of the residual from a linear market model that includes the CRSP value-weighted return on the market. ABN_VOL is a firm-specific measure of abnormal volume computed as described in Section 6. All variables are reported for the fiscal year 2001 and truncated at the $1^{\text {th }}$ and $99^{\text {th }}$ percentile of the respective distribution.

Panel B: Firm characteristics

\begin{tabular}{lrrrrrr}
\multicolumn{1}{c}{ Panel B: Firm characteristics } & \multicolumn{1}{c}{ Mean } & Std dev & p25 & Median & p75 \\
\cline { 2 - 7 } & $\mathrm{N}$ & & & & & \\
TOTASS & 1,868 & $3,585.4$ & $30,600.3$ & 94.3 & 372.9 & $1,325.5$ \\
SIZE & 1,864 & $3,389.3$ & $19,644.6$ & 99.5 & 371.0 & $1,383.1$ \\
ROA & 1,842 & -0.002 & 0.189 & -0.020 & 0.032 & 0.097 \\
CUMRET & 1,837 & 0.032 & 0.300 & -0.143 & 0.039 & 0.187 \\
DERATIO & 1,849 & 0.270 & 0.257 & 0.023 & 0.201 & 0.466 \\
MB & 1,763 & 3.777 & 3.557 & 1.904 & 2.909 & 4.441 \\
PPE_TA & 1,828 & 0.238 & 0.235 & 0.049 & 0.158 & 0.354 \\
FCSTREV & 1,257 & -0.011 & 0.045 & -0.011 & -0.001 & 0.000 \\
FIRMRETVOL & 1,867 & 0.035 & 0.021 & 0.020 & 0.030 & 0.045 \\
ABN_VOL & 1,480 & 0.105 & 0.724 & -0.377 & -0.110 & 0.352 \\
\hline
\end{tabular}




\section{Table 2}

\section{Descriptive statistics on model parameter estimates, systematic risk and beta shocks}

Panel A reports descriptive statistics for the parameter estimates from the regime switching beta model in equations (B1) and (B2), measures of systematic risk over four time periods and the beta shocks. The pre-event period beta is equal to $\hat{b}_{i 1}$ (BETA_PRE). During the event period, $\hat{\beta}_{i 2}=\hat{b}_{i 1}+\hat{b}_{i 2}(T 1-t)(t-T 2)+\hat{b}_{i 3}(t-T 1)$. We compute the event period beta (BETA_EVT) at day $\mathrm{t}=0$. The pre-report period beta (BETA_REM) is $\hat{\beta}_{i 3}=\hat{b}_{i 1}+\hat{b}_{i 3}(T 2-T 1)$. We report parameter and beta estimates choosing T1 and T2 according to Window 1 in Appendix A.2. During the postreport period, systematic risk (BETA_POST) is estimated using a market model from May 1, 2002 to August 31, 2002. The initial shock (INIT_SHOCK) is BETA_EVT - BETA_PRE. The remaining shock (REM_SHOCK) is BETA_REM - BETA_PRE.

\section{Panel A:}

Model parameters

$\hat{b}_{i 1}$

$\hat{b}_{i 2}$

$\hat{b}_{i 3}$

Estimates of systematic risk

$\begin{array}{llllll}1,868 & 0.66684 & 0.6898 & 0.18972 & 0.53558 & 0.95633 \\ 1,868 & 0.59982 & 0.97357 & -0.00566 & 0.54162 & 1.12409 \\ 1,868 & 0.74266 & 1.01538 & 0.08332 & 0.68691 & 1.27465 \\ 1,797 & 0.67755 & 0.47763 & 0.30236 & 0.67339 & 0.97329\end{array}$

Estimates of shocks

$\begin{array}{lllllll}\text { INIT_SHOCK } & 1,868 & -0.06702 & 0.94982 & -0.56727 & -0.01294 & 0.42015 \\ \text { REM_SHOCK } & 1,868 & 0.07582 & 0.91106 & -0.35574 & 0.10998 & 0.55355\end{array}$


Table 2 (continued)

Descriptive statistics on model parameter estimates, systematic risk and beta shocks

Panel B reports the means for the initial and the remaining shock by industry as well as the proportions of positive initial and remaining shocks in each industry. We report only industries with more than 5 sample observations.

\begin{tabular}{|c|c|c|c|c|c|c|c|}
\hline SIC & & $\mathrm{N}$ & INIT SHOCK & $\%$ POS & $\mathrm{N}$ & REM SHOCK & $\%$ POS \\
\hline 25 & Furniture and Fixtures & 6 & 0.6402 & 0.8333 & 6 & 0.5301 & 0.8333 \\
\hline 55 & Auto Dealers, Gas Stations & 9 & 0.5488 & 0.7778 & 9 & 0.2675 & 0.7778 \\
\hline 15 & Bldg Cnstr-Gen Contr, Op Bldr & 10 & 0.5215 & 0.8000 & 10 & 0.3981 & 0.9000 \\
\hline 24 & Lumber and Wood Pds, Ex Furn & 7 & 0.4201 & 0.7143 & 7 & 0.1426 & 0.7143 \\
\hline 23 & Apparel \& Other Finished Pds & 6 & 0.3861 & 0.6667 & 6 & 0.2990 & 0.8333 \\
\hline 72 & Personal Services & 7 & 0.3260 & 0.5714 & 7 & 0.7008 & 1.0000 \\
\hline 57 & Home Furniture \& Equip Store & 6 & 0.2949 & 0.6667 & 6 & -0.3993 & 0.3333 \\
\hline 82 & Educational Services & 6 & 0.2640 & 0.6667 & 6 & 0.1451 & 0.6667 \\
\hline 29 & Pete Refining \& Related Inds & 8 & 0.2596 & 0.3750 & 8 & -0.1416 & 0.7500 \\
\hline 34 & Fabr Metal, Ex Machy, Trans Eq & 29 & 0.2083 & 0.6207 & 29 & 0.2081 & 0.6552 \\
\hline 31 & Leather and Leather Products & 9 & 0.1957 & 0.6667 & 9 & 0.4491 & 0.7778 \\
\hline 40 & Railroad Transportation & 6 & 0.1714 & 0.6667 & 6 & 0.2418 & 0.6667 \\
\hline 65 & Real Estate & 20 & 0.1324 & 0.5500 & 20 & 0.1214 & 0.4500 \\
\hline 37 & Transportation Equipment & 35 & 0.1151 & 0.6571 & 35 & 0.1690 & 0.5714 \\
\hline 49 & Electric, Gas, Sanitary Serv & 59 & 0.0988 & 0.5593 & 59 & 0.0746 & 0.4746 \\
\hline 20 & Food and Kindred Products & 36 & 0.0848 & 0.5278 & 36 & 0.0638 & 0.4722 \\
\hline 79 & Amusements, Recreation & 16 & 0.0715 & 0.5000 & 16 & 0.1330 & 0.6250 \\
\hline 30 & Rubber \& Misc Plastics Prods & 22 & 0.0622 & 0.6364 & 22 & -0.1174 & 0.5455 \\
\hline 62 & Security \& Commodity Brokers & 21 & 0.0618 & 0.6667 & 21 & 0.3465 & 0.7143 \\
\hline 61 & Nondepository Credit Instn & 17 & 0.0591 & 0.5294 & 17 & 0.5249 & 0.6471 \\
\hline 17 & Construction-Special Trade & 6 & 0.0540 & 0.6667 & 6 & -0.0408 & 0.3333 \\
\hline 64 & Ins Agents, Brokers \& Service & 8 & 0.0471 & 0.3750 & 8 & -0.0381 & 0.3750 \\
\hline 48 & Communications & 59 & 0.0398 & 0.5932 & 59 & 0.3605 & 0.6441 \\
\hline 27 & Printing, Publishing \& Allied & 24 & 0.0311 & 0.5417 & 24 & 0.2801 & 0.7083 \\
\hline 58 & Eating and Drinking Places & 24 & 0.0205 & 0.4167 & 24 & 0.1284 & 0.7083 \\
\hline 60 & Depository Institutions & 252 & 0.0162 & 0.5278 & 252 & 0.1332 & 0.6071 \\
\hline 67 & Holding, Other Invest Offices & 29 & -0.0213 & 0.5862 & 29 & 0.0816 & 0.5517 \\
\hline 35 & Indl,Comml Machy, Computer Eq & 93 & -0.0294 & 0.5807 & 93 & -0.0468 & 0.5484 \\
\hline 80 & Health Services & 39 & -0.0440 & 0.4359 & 39 & -0.2189 & 0.3590 \\
\hline 26 & Paper and Allied Products & 17 & -0.0767 & 0.5882 & 17 & 0.1145 & 0.5294 \\
\hline 38 & Meas Instr; PhotoGds; Watches & 96 & -0.0816 & 0.4167 & 96 & -0.0812 & 0.4896 \\
\hline 32 & Stone, Clay, Glass, Concrete Pd & 15 & -0.0823 & 0.5333 & 15 & 0.2790 & 0.7333 \\
\hline 39 & Misc Manufacturing Industries & 15 & -0.0933 & 0.4667 & 15 & -0.4003 & 0.4667 \\
\hline 33 & Primary Metal Industries & 27 & -0.1140 & 0.3704 & 27 & 0.3667 & 0.6296 \\
\hline 36 & Electr, Oth Elec Eq, Ex Cmp & 113 & -0.1332 & 0.4336 & 113 & 0.0753 & 0.5487 \\
\hline 13 & Oil and Gas Extraction & 71 & -0.1358 & 0.4366 & 71 & 0.4118 & 0.8028 \\
\hline 73 & Business Services & 217 & -0.1411 & 0.4839 & 217 & 0.0467 & 0.5438 \\
\hline 50 & Durable Goods-Wholesale & 49 & -0.1631 & 0.4082 & 49 & 0.2468 & 0.5306 \\
\hline 47 & Transportation Services & 6 & -0.2330 & 0.3333 & 6 & 0.0114 & 0.5000 \\
\hline 51 & Nondurable Goods-Wholesale & 22 & -0.2421 & 0.4091 & 22 & 0.2576 & 0.6818 \\
\hline 28 & Chemicals \& Allied Products & 163 & -0.2812 & 0.4110 & 163 & -0.2656 & 0.3742 \\
\hline 10 & Metal Mining & 10 & -0.2854 & 0.5000 & 10 & 0.3835 & 0.7000 \\
\hline 42 & Motor Freight Trans, Warehouse & 21 & -0.2957 & 0.3810 & 21 & 0.1334 & 0.6667 \\
\hline 59 & Miscellaneous Retail & 19 & -0.3042 & 0.3684 & 19 & 0.0181 & 0.6842 \\
\hline 70 & Hotels, Other Lodging Places & 17 & -0.3445 & 0.2941 & 17 & -0.0311 & 0.5294 \\
\hline 87 & Engr, Acc,Resh, Mgmt, Rel Sves & 53 & -0.3662 & 0.3396 & 53 & -0.3568 & 0.3208 \\
\hline 44 & Water Transportation & 10 & -0.4219 & 0.4000 & 10 & 0.3883 & 0.8000 \\
\hline 78 & Motion Pictures & 6 & -0.5024 & 0.5000 & 6 & 0.7753 & 1.0000 \\
\hline 16 & Heavy Constr; not Bldg Cntractrs & 8 & -0.5086 & 0.2500 & 8 & 0.4448 & 0.5000 \\
\hline 22 & Textile Mill Products & 8 & -0.7936 & 0.5000 & 8 & 0.0101 & 0.5000 \\
\hline
\end{tabular}




\section{Figure 1}

Illustrations of the time-series patterns in the systematic risk estimates for the pre-event period, the event period, and the pre-report period for alternative values of $\hat{b}_{i 2}$. Panels A through C illustrate levels of systematic risk in the case of a HIGH positive $\hat{b}_{i 2}$ (equals 0.100 ), a LOW positive $\hat{b}_{i 2}$ (equals 0.002 ), and a negative $\hat{b}_{i 2}$ (equals -0.002), respectively. Within each panel, we present estimates of systematic risk in the pre-report period for five levels of $\hat{b}_{i 3}$.

Panel A: HIGH Positive $\hat{b}_{i 2}$

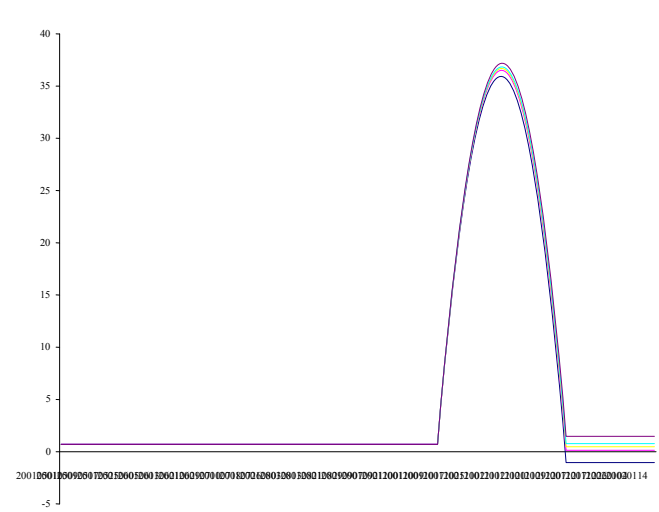

Panel B: LOW Positive $\hat{b}_{i 2}$

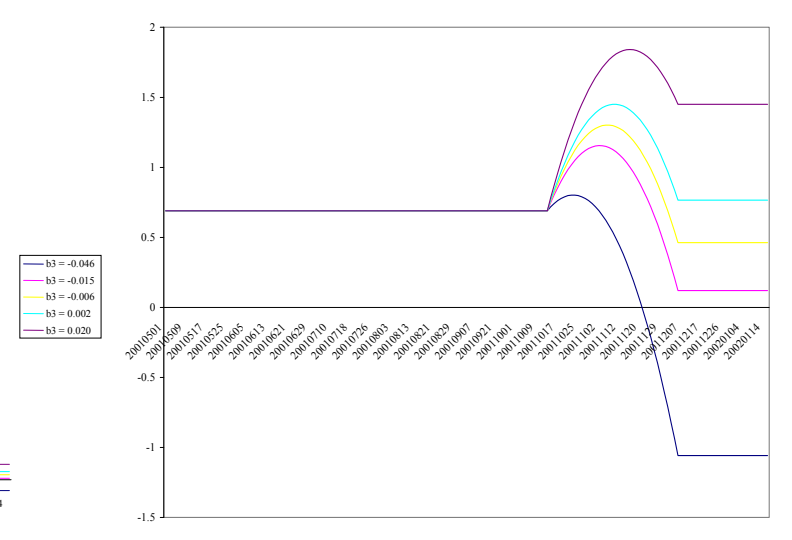

Panel C: Negative $\hat{b}_{i 2}$

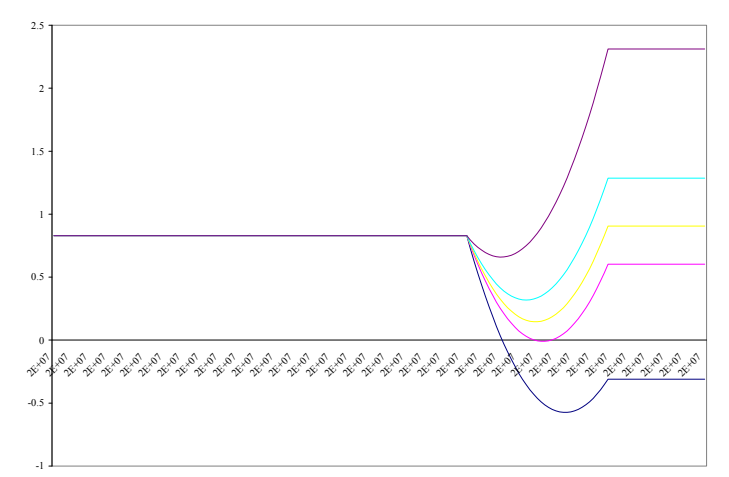




\section{Table 3}

\section{Relation between 10-K disclosure changes and cost of capital shocks}

The sample comprises a maximum of 1,868 firms with a December fiscal year end and sufficient data to estimate subsequent models. We eliminate airlines, insurance carriers, and firms that are majorly affected by the September $11^{\text {th }}$ terrorist attacks as described in Section 3. Panel A reports results for eight models regressing the percent change in page counts (\% $\%$ PAGES) on combinations of initial shock (INIT_SHOCK), remaining shock (REM_SHOCK), pre-event beta (BETA_PRE), and control variables. LASSETS is natural log of total assets. ROA is the return on assets. DERATIO is long-term debt scaled by total assets. MB is the market-to-book ratio. PPE/TA is the book value of net PPE scaled by total assets. The control variables are measured as of fiscal year 2000. The changes in the control variables are measured from 2000 to 2001, except in for the market-to-book ratio which uses the market values of equity. The regression models include, wherever noted, industry-fixed effects based on one-digit SIC codes and a separate dummy for firms in Enronrelated industries (defined as SIC2 equal to 13, 29 or 49). The t-statistics are reported in parentheses and based on standard errors that are clustered at two-digit SIC level. ${ }^{* *}\left\{{ }^{*}\right\}\left({ }^{*}\right)$ indicate significance at the $1 \%, 5 \%, 10 \%$ level (two-sided).

Panel A:

\begin{tabular}{|c|c|c|c|c|c|c|c|c|}
\hline & \multicolumn{8}{|c|}{ Model specification } \\
\hline & (1) & (2) & (3) & (4) & (5) & (6) & (7) & (8) \\
\hline Constant & $\begin{array}{c}0.1072 * * * \\
(4.17)\end{array}$ & $\begin{array}{c}0.1015^{*} \\
(1.92)\end{array}$ & $\begin{array}{l}0.0697 \\
(1.27)\end{array}$ & $\begin{array}{c}0.1274 * * * \\
(3.02)\end{array}$ & $\begin{array}{c}0.1057 * * * \\
(4.02)\end{array}$ & $\begin{array}{c}0.1067^{* *} \\
(2.03)\end{array}$ & $\begin{array}{l}0.0602 \\
(1.11)\end{array}$ & $\begin{array}{c}0.1173 * * * \\
(2.93)\end{array}$ \\
\hline INIT_SHOCK & $\begin{array}{c}0.0289 * * * \\
(4.25)\end{array}$ & $\begin{array}{c}0.0259 * * * \\
(3.88)\end{array}$ & $\begin{array}{c}0.0231 * * * \\
(3.56)\end{array}$ & $\begin{array}{c}0.0255^{* * *} \\
\quad(3.68)\end{array}$ & & & & \\
\hline REM_SHOCK & & & & & $\begin{array}{c}0.0237 * * * \\
(2.88)\end{array}$ & $\begin{array}{c}0.0242 * * * \\
(3.15)\end{array}$ & $\begin{array}{c}0.0174 * \\
(1.85)\end{array}$ & $\begin{array}{c}0.0207 * * \\
(2.23)\end{array}$ \\
\hline BETA_PRE & $\begin{array}{c}0.0501 * * * \\
\quad(3.21)\end{array}$ & $\begin{array}{c}0.0434^{* *} \\
(2.36)\end{array}$ & $\begin{array}{c}0.0431^{* *} \\
(2.27)\end{array}$ & $\begin{array}{c}0.0463 * * * \\
\quad(2.81)\end{array}$ & $\begin{array}{c}0.0429 * * * \\
\quad(2.80)\end{array}$ & $\begin{array}{c}0.0368^{* *} \\
(2.03)\end{array}$ & $\begin{array}{c}0.0359^{*} \\
(1.87)\end{array}$ & $\begin{array}{c}0.0401^{* *} \\
(2.38)\end{array}$ \\
\hline LASSETS $_{2000}$ & $\begin{array}{c}0.0055 \\
(1.19)\end{array}$ & $\begin{array}{c}0.0078^{* *} \\
(2.10)\end{array}$ & $\begin{array}{c}0.0080^{* *} \\
(2.29)\end{array}$ & & $\begin{array}{c}0.0062 \\
(1.32)\end{array}$ & $\begin{array}{c}0.0085^{* *} \\
(2.13)\end{array}$ & $\begin{array}{c}0.0092^{* *} \\
(2.30)\end{array}$ & \\
\hline $\mathrm{ROA}_{2000}$ & $\begin{array}{c}0.0089 \\
(0.40)\end{array}$ & $\begin{array}{l}0.0006 \\
(0.03)\end{array}$ & $\begin{array}{c}-0.0524 \\
(1.48)\end{array}$ & & $\begin{array}{c}0.0074 \\
(0.33)\end{array}$ & $\begin{array}{l}0.0006 \\
(0.03)\end{array}$ & $\begin{array}{c}-0.0515 \\
(1.56)\end{array}$ & \\
\hline DERATIO $_{2000}$ & $\begin{array}{c}-0.0180 \\
(0.54)\end{array}$ & $\begin{array}{l}0.0017 \\
(0.05)\end{array}$ & $\begin{array}{c}0.0068 \\
(0.19)\end{array}$ & & $\begin{array}{c}-0.0239 \\
(0.74)\end{array}$ & $\begin{array}{l}0.0014 \\
(0.04)\end{array}$ & $\begin{array}{c}0.0054 \\
(0.15)\end{array}$ & \\
\hline $\mathrm{MB}_{2000}$ & & $\begin{array}{c}-0.0004^{*} \\
(1.77)\end{array}$ & $\begin{array}{c}-0.0006 \\
(0.76)\end{array}$ & & & $\begin{array}{c}-0.0003 \\
(1.61)\end{array}$ & $\begin{array}{c}-0.0006 \\
(0.75)\end{array}$ & \\
\hline $\mathrm{PPE} / \mathrm{TA}_{2000}$ & & $\begin{array}{c}0.0432 \\
(0.68)\end{array}$ & $\begin{array}{c}0.0433 \\
(0.64)\end{array}$ & & & $\begin{array}{c}0.0316 \\
(0.50)\end{array}$ & $\begin{array}{l}0.0337 \\
(0.50)\end{array}$ & \\
\hline$\triangle \mathrm{ASSETS}$ & & & $\begin{array}{c}0.0573 * * \\
(2.15)\end{array}$ & $\begin{array}{c}0.0506^{* *} \\
(2.03)\end{array}$ & & & $\begin{array}{c}0.0607 * * \\
(2.35)\end{array}$ & $\begin{array}{c}0.0544^{* *} \\
(2.24)\end{array}$ \\
\hline$\triangle \mathrm{ROA}$ & & & $\begin{array}{c}-0.1826^{* *} \\
(2.40)\end{array}$ & $\begin{array}{c}-0.1423^{*} \\
(1.71)\end{array}$ & & & $\begin{array}{c}-0.1718^{* *} \\
(2.29)\end{array}$ & $\begin{array}{c}-0.1294 \\
(1.54)\end{array}$ \\
\hline$\triangle$ DERATIO & & & $\begin{array}{l}0.0217 \\
(0.29)\end{array}$ & $\begin{array}{c}0.0372 \\
(0.52)\end{array}$ & & & $\begin{array}{l}0.0179 \\
(0.24)\end{array}$ & $\begin{array}{l}0.0324 \\
(0.46)\end{array}$ \\
\hline$\Delta \mathrm{MB}$ & & & $\begin{array}{l}0.0147 \\
(1.26)\end{array}$ & $\begin{array}{c}0.0177^{*} \\
(1.71)\end{array}$ & & & $\begin{array}{l}0.0151 \\
(1.35)\end{array}$ & $\begin{array}{c}0.0175^{*} \\
(1.77)\end{array}$ \\
\hline Industry controls & NO & YES & YES & YES & NO & YES & YES & YES \\
\hline Observations & 1,868 & 1,793 & 1,687 & 1,707 & 1,868 & 1,793 & 1,687 & 1,707 \\
\hline R-squared & 0.0169 & 0.0245 & 0.0253 & 0.0236 & 0.0147 & 0.0237 & 0.0236 & 0.0218 \\
\hline
\end{tabular}




\section{Table 3 (continued)}

\section{Relation between 10-K disclosure changes and cost of capital shocks}

Panel B reports results for regression models of percent changes in page counts for three sections of the 10-K and one section from the proxy statement on combinations of initial shock (INIT SHOCK), remaining shock (REM SHOCK), pre-event beta (BETA PRE), and control variables (described in Panel A).

The percentage changes in the page counts refer to the management discussion $\&$ analysis $(\% \Delta \mathrm{MDA})$, the sections that are generally narrative (\% $\%$ DISCUSS) and the sections that include financial tables $(\% \Delta \mathrm{FS})$. See Table 1, Panel A for more details. The regression models include industry-fixed effects based on onedigit SIC codes and a separate dummy for firms in Enron-related industries (defined as SIC2 equal to 13, 29 or 49). The t-statistics are reported in parentheses and based on standard errors that are clustered at two-digit SIC level. *** $\{* *\}\left(^{*}\right)$ indicate significance at the $1 \%, 5 \%, 10 \%$ level (two-sided).

\begin{tabular}{|c|c|c|c|c|c|c|c|c|}
\hline \multicolumn{9}{|c|}{ Dependent variable } \\
\hline \multirow{3}{*}{ Constant } & $\% \Delta \mathrm{MDA}$ & $\% \Delta$ DISCUSS & $\% \Delta \mathrm{FS}$ & $\% \triangle \mathrm{REL}$ PAR & $\% \Delta \mathrm{MDA}$ & $\% \Delta$ DISCUSS & $\% \Delta \mathrm{FS}$ & $\% \triangle$ REL PAR \\
\hline & $0.3903 * * *$ & $0.1394 * * *$ & 0.0631 & 0.4637 & $0.3916^{* * *}$ & $0.1325 * * *$ & 0.0791 & 0.4513 \\
\hline & $(3.49)$ & $(2.85)$ & $(0.98)$ & $(1.56)$ & $(3.60)$ & $(2.72)$ & $(1.23)$ & $(1.50)$ \\
\hline \multirow{2}{*}{ INIT_SHOCK } & 0.0166 & 0.0193 & $0.0343 * * *$ & 0.0343 & & & & \\
\hline & $(1.37)$ & $(1.63)$ & $(2.84)$ & $(0.98)$ & & & & \\
\hline \multirow[t]{2}{*}{ REM_SHOCK } & & & & & 0.0086 & $0.0181 *$ & $0.0492 *$ & $0.0473 *$ \\
\hline & & & & & $(0.62)$ & $(1.88)$ & $(1.70)$ & $(1.72)$ \\
\hline \multirow[t]{2}{*}{ BETA_PRE } & 0.0352 & 0.0149 & $0.0640 * *$ & 0.0037 & 0.0278 & 0.0091 & 0.0594 & 0.0008 \\
\hline & $(1.37)$ & $(0.58)$ & $(2.06)$ & $(0.07)$ & $(1.08)$ & $(0.38)$ & $(1.62)$ & $(0.02)$ \\
\hline \multirow[t]{2}{*}{ LASSETS $_{2000}$} & 0.0110 & 0.0102 & 0.0108 & -0.0065 & 0.0122 & 0.0108 & 0.0104 & -0.0068 \\
\hline & $(1.23)$ & $(1.10)$ & $(1.19)$ & $(0.38)$ & $(1.39)$ & $(1.30)$ & $(0.98)$ & $(0.44)$ \\
\hline \multirow[t]{2}{*}{$\mathrm{ROA}_{2000}$} & -0.0160 & $0.0611 * *$ & 0.0172 & -0.1202 & -0.0184 & $0.0570 *$ & 0.0080 & -0.1212 \\
\hline & $(0.35)$ & $(2.04)$ & $(0.44)$ & $(1.15)$ & $(0.40)$ & $(1.97)$ & $(0.21)$ & $(1.13)$ \\
\hline \multirow[t]{2}{*}{ DERATIO $_{2000}$} & $-0.1149 * *$ & -0.0627 & -0.0060 & 0.0448 & $-0.1185 * *$ & -0.0625 & 0.0038 & 0.0500 \\
\hline & $(2.03)$ & $(1.31)$ & $(0.08)$ & $(0.36)$ & $(2.01)$ & $(1.38)$ & $(0.05)$ & $(0.39)$ \\
\hline \multirow[t]{2}{*}{$\mathrm{MB}_{2000}$} & 0.0000 & -0.0003 & $-0.0009 * *$ & 0.0008 & 0.0001 & -0.0003 & $-0.0009 * *$ & 0.0007 \\
\hline & $(0.07)$ & $(1.00)$ & $(2.30)$ & $(0.21)$ & $(0.09)$ & $(1.06)$ & $(2.27)$ & $(0.20)$ \\
\hline \multirow[t]{2}{*}{$\mathrm{PPE} / \mathrm{TA}_{2000}$} & -0.0176 & $-0.0989 * *$ & 0.1003 & -0.1234 & -0.0224 & $-0.1074 * *$ & 0.0819 & -0.1428 \\
\hline & $(0.28)$ & $(2.02)$ & $(1.03)$ & $(0.69)$ & $(0.36)$ & $(2.23)$ & $(0.90)$ & $(0.80)$ \\
\hline Industry controls & YES & YES & YES & YES & YES & YES & YES & YES \\
\hline Observations & 1,069 & 1,109 & 1,096 & 1,257 & 1,069 & 1,109 & 1,096 & 1,257 \\
\hline R-squared & 0.0505 & 0.0411 & 0.0163 & 0.0107 & 0.0496 & 0.0405 & 0.0192 & 0.0114 \\
\hline
\end{tabular}




\section{Table 3 (continued)}

\section{Robustness analysis with respect to the beta shocks}

Robustness analysis of the results presented in Table 3 . All of the models regress the percent change in page counts $(\% \Delta \mathrm{PAGES})$ on either the initial shock or remaining shock, the pre-event beta, and the control variables from Models (3) and (7) in Table 3. In Model 1, INIT SHOCK, REM SHOCK, and the pre-event beta are estimated using coefficient estimates from a linear market model that includes the CRSP value-weighted return on the market, rather than from the quadratic model described in Table 2. In Model 2, the sample excludes firms with a stock price at December 31, 2001 of less than \$5. In Model 3, we include an additional control variable that measures the change in the mean (consensus) analyst forecast of next-fiscal-year annual earnings during the period from August 2001 to December 2001 scaled by price (FCSTREV). In Model 4, we include an additional control variable that measures the firm's idiosyncratic risk during the pre-event period (FIRMRETVOL). Idiosyncratic risk is the standard deviation of the residual from the linear market model that includes the CRSP valueweighted return on the market. The t-statistics are reported in parentheses and are based on standard errors that are clustered at the two-digit SIC level. *** $\{* *\}$ (*) indicate significance at the $1 \%, 5 \%, 10 \%$ level (two-sided).

\section{Panel C:}

\section{(1)}

Shocks computed using linear market-model betas

(2)

Sample excludes stocks with price $<\$ 5$

$$
\text { (3) }
$$

Model includes control for analyst forecast revision activity

\begin{tabular}{llllllll}
\hline & & & & & \\
0.0593 & 0.0506 & 0.1054 & 0.0910 & $0.1624 * * *$ & $0.1694 * * *$ & 0.0438 & 0.0479 \\
$(1.12)$ & $(0.97)$ & $(1.62)$ & $(1.45)$ & $(2.85)$ & $(2.90)$ & $(0.71)$ & $(0.80)$ \\
$0.0428^{* * *}$ & & $0.0308^{* * *}$ & & $0.0276^{* * *}$ & & $0.0248^{* * *}$ & \\
$(3.82)$ & & $(3.34)$ & & $(2.70)$ & $0.0327 * * *$ & $(3.54)$ & $0.0229 * * *$ \\
& $0.0211^{* * *}$ & & $0.0323 * * *$ & & $(3.24)$ & & $(3.00)$
\end{tabular}

Additional control variables:

FCSTREV

FIRMRETVOL

INIT_SHOCK

REM_SHOCK

$\begin{array}{cc}-0.2652 * & -0.2935^{*} \\ (1.68) & (1.89)\end{array}$

All controls

YES

YES

YES

1,784

Observations

0.0282
1,784

0.0245

0.0219

YES
1,387
0.0224

YES

$$
\text { (2.10) }
$$


Table 4

Cross-sectional analysis of the relation between disclosure changes and cost of capital shocks

Panels A and B present results on the relation between the beta shocks and firms' disclosure choices for firms with a positive beta shock and high financing needs. The first four columns present results partitioning the sample based on a positive initial or remaining shock and high financing needs (POS\&HIGH=1), where the latter is defined as having a cash flow from investing activities scaled by total assets above the sample median. The last four columns present results partitioning the sample based on a positive initial or remaining shock and high financing needs (POS\&HIGH=1), where the latter is defined as having external financing needs above the median for the sample. External financing needs are measured as the difference between a firm's average asset growth rate over two years and the maximum growth it can finance internally, which is ROA/(1-ROA), where ROA is income before extraordinary items over total assets. Panel A presents results for the percent change in the page counts of the $10-\mathrm{K}(\% \Delta \mathrm{PAGES})$. Panel $\mathrm{B}$ presents results for the percent change in the page counts in the MD\&A (\% $\%$ MDA). The regression models include control variables as defined for Models (2) and (6) in Table 3 and industry-fixed effects based on one-digit SIC codes and a binary indicator for Enron-related industries. The coefficients of the control variables are not presented. The t-statistics are reported in parentheses and based on standard errors that are clustered at two-digit SIC level. *** $\{* *\}(*)$ indicate significance at the $1 \%, 5 \%, 10 \%$ level (two-sided). The last row presents the p-value of a (Chow) test whether the coefficients on the beta shock are statistically different across the two subsamples.

\begin{tabular}{|c|c|c|c|c|c|c|c|c|}
\hline & $(1)$ & $(2)$ & (3) & $(4)$ & $(5)$ & $(6)$ & $(7)$ & $(8)$ \\
\hline \multirow[t]{3}{*}{ Proxy for financing needs: } & \multicolumn{4}{|c|}{ Cash flow from Investment } & \multicolumn{4}{|c|}{ External financing needs } \\
\hline & \multicolumn{2}{|c|}{ POS\&HIGH } & \multicolumn{2}{|c|}{ POS\&HIGH } & \multicolumn{2}{|c|}{ POS\&HIGH } & \multicolumn{2}{|c|}{ POS\&HIGH } \\
\hline & $=1$ & $=0$ & $=1$ & $=0$ & $=1$ & $=0$ & $=1$ & $=0$ \\
\hline \multicolumn{9}{|c|}{ Panel A: \% page changes in the $10-K$} \\
\hline Constant & $\begin{array}{c}0.1563 \\
(1.12)\end{array}$ & $\begin{array}{c}0.1155^{* *} \\
(2.52)\end{array}$ & $\begin{array}{c}-0.0149 \\
(-0.22)\end{array}$ & $\begin{array}{c}0.0946 * * \\
(2.49)\end{array}$ & $\begin{array}{c}0.0482 \\
(0.72)\end{array}$ & $\begin{array}{c}0.1097 * \\
(1.83)\end{array}$ & $\begin{array}{c}-0.0224 \\
(-0.32)\end{array}$ & $\begin{array}{c}0.0034 \\
(0.08)\end{array}$ \\
\hline INIT_SHOCK & $\begin{array}{c}0.0521^{* *} \\
(2.04)\end{array}$ & $\begin{array}{c}0.0167 * * \\
(2.25)\end{array}$ & & & $\begin{array}{c}0.0348 \\
(1.44)\end{array}$ & $\begin{array}{c}0.0202 * * \\
(2.34)\end{array}$ & & \\
\hline REM_SHOCK & & & $\begin{array}{c}0.0495 \\
(1.31)\end{array}$ & $\begin{array}{c}0.0108 \\
(1.27)\end{array}$ & & & $\begin{array}{c}0.0669^{* *} \\
(2.53)\end{array}$ & $\begin{array}{c}0.0101 \\
(1.02)\end{array}$ \\
\hline All controls & YES & YES & YES & YES & YES & YES & YES & YES \\
\hline Observations & 376 & 1,127 & 433 & 1,070 & 444 & 1,349 & 512 & 1,281 \\
\hline R-squared & 0.0285 & 0.0286 & 0.0498 & 0.0237 & 0.0347 & 0.0249 & 0.0466 & 0.0260 \\
\hline $\mathrm{p}$-value for difference & \multicolumn{2}{|c|}{0.1401} & \multicolumn{2}{|r|}{0.3075} & \multicolumn{2}{|r|}{0.5743} & \multicolumn{2}{|c|}{0.0389} \\
\hline \multicolumn{9}{|c|}{ Panel B: \% page changes in MDA } \\
\hline Constant & $\begin{array}{c}0.6157 \\
(1.32)\end{array}$ & $\begin{array}{c}0.2729 * * * \\
(3.44)\end{array}$ & $\begin{array}{c}0.6980 \\
(1.50)\end{array}$ & $\begin{array}{c}0.2747 * * * \\
(3.52)\end{array}$ & $\begin{array}{c}0.2116^{*} \\
(1.82)\end{array}$ & $\begin{array}{c}0.2994 * * * \\
(4.08)\end{array}$ & $\begin{array}{c}0.2564 * * \\
(2.54)\end{array}$ & $\begin{array}{c}0.3096 * * * \\
(4.25)\end{array}$ \\
\hline INIT_SHOCK & $\begin{array}{c}0.1121^{* *} \\
(2.03)\end{array}$ & $\begin{array}{c}-0.0049 \\
(-0.35)\end{array}$ & & & $\begin{array}{c}0.0509 \\
(1.07)\end{array}$ & $\begin{array}{c}-0.0144 \\
(-1.01)\end{array}$ & & \\
\hline REM_SHOCK & & & $\begin{array}{c}0.0447 \\
(0.90)\end{array}$ & $\begin{array}{c}-0.0117 \\
(-0.71)\end{array}$ & & & $\begin{array}{c}0.0106 \\
(0.28)\end{array}$ & $\begin{array}{c}0.0031 \\
(0.19)\end{array}$ \\
\hline All controls & YES & YES & YES & YES & YES & YES & YES & YES \\
\hline Observations & 232 & 695 & 232 & 695 & 280 & 789 & 280 & 789 \\
\hline R-squared & 0.1066 & 0.0249 & 0.0968 & 0.0255 & 0.0627 & 0.0589 & 0.0600 & 0.0581 \\
\hline p-value for difference & & 78 & & 0.2718 & & 0.1515 & & 85 \\
\hline
\end{tabular}




\section{Table 4 (continued)}

\section{Cross-sectional analysis of the relation between disclosure changes and cost of capital shocks}

Panel C results on the relation between the beta shocks and firms' disclosure choices for Arthur Andersen audit clients versus other firms. The first two columns use \% $\%$ PAGES as dependent variable. The next columns focus on page changes in the MD\&A and the last two columns report results for regressions using $\% \triangle R E L \_P A R$. The regression models include control variables as defined for Models (2) and (6) in Table 3 and industry-fixed effects based on one-digit SIC codes and a binary indicator for Enron-related industries. The t-statistics are reported in parentheses and based on standard errors that are clustered at two-digit SIC level. ${ }^{* *}\left\{{ }^{* *}\right\}\left({ }^{*}\right)$ indicate significance at the $1 \%, 5 \%, 10 \%$ level (two-sided). The last row presents the p-value of a (Chow) test whether the coefficients on the beta shock are statistically different across the two subsamples.

\section{Panel C: Split by auditor}

\begin{tabular}{|c|c|c|c|c|c|c|}
\hline \multirow[b]{3}{*}{ Constant } & \multicolumn{2}{|c|}{$\% \triangle$ PAGES } & \multicolumn{2}{|c|}{$\% \Delta \mathrm{MDA}$} & \multicolumn{2}{|c|}{$\% \triangle R E L \_P A R$} \\
\hline & AA clients & Non-AA clients & AA clients & Non-AA clients & AA clients & Non-AA clients \\
\hline & $\begin{array}{c}0.1307 \\
(1.20)\end{array}$ & $\begin{array}{c}0.0211 \\
(0.38)\end{array}$ & $\begin{array}{c}0.3094 * * \\
(2.07)\end{array}$ & $\begin{array}{c}0.3931 * * * \\
(5.01)\end{array}$ & $\begin{array}{c}0.1515 \\
(0.34)\end{array}$ & $\begin{array}{c}0.4364^{* *} \\
(2.00)\end{array}$ \\
\hline INIT_SHOCK & $\begin{array}{l}0.0612 * * * \\
\quad(2.74)\end{array}$ & $\begin{array}{c}0.0193 * * \\
(2.11)\end{array}$ & $\begin{array}{l}0.0241 \\
(0.75)\end{array}$ & $\begin{array}{c}0.0149 \\
(0.91)\end{array}$ & $\begin{array}{c}0.2990 * * * \\
(3.66)\end{array}$ & $\begin{array}{c}-0.0222 \\
(0.66)\end{array}$ \\
\hline BETA_PRE & $\begin{array}{c}0.0519 \\
(1.54)\end{array}$ & $\begin{array}{l}0.0434 * * * \\
\quad(3.01)\end{array}$ & $\begin{array}{c}0.0044 \\
(0.09)\end{array}$ & $\begin{array}{l}0.0319 \\
(1.19)\end{array}$ & $\begin{array}{c}0.2084^{*} \\
(1.65)\end{array}$ & $\begin{array}{c}-0.0435 \\
(0.81)\end{array}$ \\
\hline All controls & YES & YES & YES & YES & YES & YES \\
\hline $\begin{array}{l}\text { Observations } \\
\text { R-squared } \\
\text { p-value for difference }\end{array}$ & $\begin{array}{c}333 \\
0.0764\end{array}$ & $\begin{array}{c}1,460 \\
0.0205\end{array}$ & $\begin{array}{c}206 \\
0.0755\end{array}$ & $\begin{array}{c}863 \\
0.0644\end{array}$ & $\begin{array}{c}249 \\
0.1083\end{array}$ & $\begin{array}{c}1,008 \\
0.0104\end{array}$ \\
\hline
\end{tabular}


Table 5

\section{Relation between 10-K disclosure changes and cost of capital shocks controlling for interim disclosure changes}

Results from regressions of the percent change in pages (\% $\%$ PAGES) on the cost of capital shocks and proxies for firms' interim disclosures. The interim disclosure proxies are: $\triangle 8 \mathrm{KCOUNT}$, which equals the change in the number of 8-K filings from 2000 to 2001; $\Delta \mathrm{CALL}$, which equals the change in the number of conference calls; $\% \Delta$ WORDS, which is the percentage change in the number of words in the fourth quarter 2001 earnings announcement; and a market-based measure of interim disclosure, the parameter $\hat{b}_{\mathrm{i} 2}$ from the regime-switching model. See Tables 1 and 2 for more details on these variables. All models include control variables as defined for Models (2) and (6) in Table 3 and industry-fixed effects based on one-digit SIC codes and a binary indicator for Enron-related industries. The t-statistics are reported in parentheses and based on standard errors that are clustered at two-digit SIC level. $*^{* *}\left\{{ }^{*}\right\}\left({ }^{*}\right)$ indicate significance at the $1 \%, 5 \%, 10 \%$ level (two-sided), respectively.

\begin{tabular}{|c|c|c|c|c|c|c|c|}
\hline & (1) & (2) & (3) & (4) & (5) & (6) & (7) \\
\hline Constant & $\begin{array}{c}0.0990^{*} \\
(1.88)\end{array}$ & $\begin{array}{c}0.1040^{*} \\
(1.98)\end{array}$ & $\begin{array}{c}0.1019^{*} \\
(1.93)\end{array}$ & $\begin{array}{c}0.1070^{* *} \\
(2.03)\end{array}$ & $\begin{array}{l}0.0603 \\
(1.07)\end{array}$ & $\begin{array}{c}0.0486 \\
(0.88)\end{array}$ & $\begin{array}{c}0.1110^{* *} \\
(2.12)\end{array}$ \\
\hline INIT_SHOCK & $\begin{array}{c}0.0254 * * * \\
(3.78)\end{array}$ & & $\begin{array}{c}0.0258^{* * * *} \\
(3.87)\end{array}$ & & $\begin{array}{c}0.0259^{* * *} \\
(3.84)\end{array}$ & & \\
\hline REM_SHOCK & & $\begin{array}{c}0.0244 * * * \\
\quad(3.24)\end{array}$ & & $\begin{array}{c}0.0241 * * * \\
\quad(3.15)\end{array}$ & & $\begin{array}{c}0.0299 * * * \\
\quad(3.56)\end{array}$ & $\begin{array}{c}0.0334 * * * \\
(3.78)\end{array}$ \\
\hline BETA_PRE & $\begin{array}{c}0.0431^{* *} \\
(2.34)\end{array}$ & $\begin{array}{c}0.0369 * * \\
(2.04)\end{array}$ & $\begin{array}{c}0.0434 * * \\
(2.36)\end{array}$ & $\begin{array}{c}0.0368^{* *} \\
(2.03)\end{array}$ & $\begin{array}{c}0.0477 * * \\
(2.41)\end{array}$ & $\begin{array}{c}0.0423^{* *} \\
(2.14)\end{array}$ & $\begin{array}{c}0.0495 * * \\
(2.47)\end{array}$ \\
\hline LASSETS $_{2000}$ & $\begin{array}{c}0.0084^{* *} \\
(2.21)\end{array}$ & $\begin{array}{c}0.0091^{* *} \\
(2.23)\end{array}$ & $\begin{array}{c}0.0078^{* *} \\
(2.10)\end{array}$ & $\begin{array}{c}0.0085^{* *} \\
(2.13)\end{array}$ & $\begin{array}{c}0.0092^{* *} \\
(2.39)\end{array}$ & $\begin{array}{c}0.0095^{* *} \\
(2.30)\end{array}$ & $\begin{array}{l}0.0061 \\
(1.53)\end{array}$ \\
\hline $\mathrm{ROA}_{2000}$ & $\begin{array}{c}-0.0013 \\
(0.06)\end{array}$ & $\begin{array}{c}-0.0016 \\
(0.08)\end{array}$ & $\begin{array}{l}0.0005 \\
(0.02)\end{array}$ & $\begin{array}{l}0.0005 \\
(0.02)\end{array}$ & $\begin{array}{c}-0.0133 \\
(0.58)\end{array}$ & $\begin{array}{c}-0.0155 \\
(0.66)\end{array}$ & $\begin{array}{c}0.0011 \\
(0.05)\end{array}$ \\
\hline DERATIO $_{2000}$ & $\begin{array}{c}0.0008 \\
(0.02)\end{array}$ & $\begin{array}{c}0.0006 \\
(0.02)\end{array}$ & $\begin{array}{c}0.0016 \\
(0.05)\end{array}$ & $\begin{array}{l}0.0012 \\
(0.04)\end{array}$ & $\begin{array}{l}0.0034 \\
(0.09)\end{array}$ & $\begin{array}{l}0.0037 \\
(0.10)\end{array}$ & $\begin{array}{c}0.0083 \\
(0.24)\end{array}$ \\
\hline $\mathrm{MB}_{2000}$ & $\begin{array}{c}-0.0004^{*} \\
(1.78)\end{array}$ & $\begin{array}{c}-0.0003 \\
(1.65)\end{array}$ & $\begin{array}{c}-0.0003^{*} \\
(1.69)\end{array}$ & $\begin{array}{c}-0.0003 \\
(1.53)\end{array}$ & $\begin{array}{c}-0.0003 \\
(1.45)\end{array}$ & $\begin{array}{c}-0.0003 \\
(1.40)\end{array}$ & $\begin{array}{c}-0.0004 * \\
(1.89)\end{array}$ \\
\hline $\mathrm{PPE} / \mathrm{TA}_{2000}$ & $\begin{array}{c}0.0439 \\
(0.69)\end{array}$ & $\begin{array}{l}0.0325 \\
(0.52)\end{array}$ & $\begin{array}{l}0.0427 \\
(0.68)\end{array}$ & $\begin{array}{c}0.0312 \\
(0.50)\end{array}$ & $\begin{array}{l}0.0446 \\
(0.66)\end{array}$ & $\begin{array}{l}0.0323 \\
(0.48)\end{array}$ & $\begin{array}{c}0.0362 \\
(0.58)\end{array}$ \\
\hline Industry controls & YES & YES & YES & YES & YES & YES & YES \\
\hline$\triangle 8 \mathrm{KCOUNT}$ & $\begin{array}{c}0.0080^{*} \\
(1.77)\end{array}$ & $\begin{array}{c}0.0092 * \\
(1.96)\end{array}$ & & & & & \\
\hline$\triangle$ CALL & & & $\begin{array}{c}-0.0032 \\
(0.45)\end{array}$ & $\begin{array}{c}-0.0027 \\
(0.39)\end{array}$ & & & \\
\hline$\% \triangle \mathrm{WORDS}$ & & & & & $\begin{array}{c}0.0154 \\
(0.68)\end{array}$ & $\begin{array}{c}0.0163 \\
(0.72)\end{array}$ & \\
\hline$b_{i 2}$ & & & & & & & $\begin{array}{c}8.4903 * * * \\
(3.63)\end{array}$ \\
\hline Observations & 1,793 & 1,793 & 1,793 & 1,793 & 1,646 & 1,646 & 1,793 \\
\hline R-squared & 0.0253 & 0.0249 & 0.0245 & 0.0238 & 0.0275 & 0.0288 & 0.0279 \\
\hline
\end{tabular}




\section{Table 6 \\ Relation between interim disclosures and cost of capital shocks}

The first four columns of the table present results from four regression models of proxies for interim disclosures on combinations of initial shock (INIT_SHOCK), remaining shock (REM_SHOCK), pre-event beta (BETA_PRE), and control variables. Column 1 presents results for changes in the number of $8-\mathrm{K}$ filings as defined in Table 1 $(\triangle 8 \mathrm{KCOUNT})$. In Column 2, we restrict the analysis to changes in the number of 8-K filings during the second-half of the event period and hence before the pre-report period during which the remaining shock is measured. Column 3 presents results for changes in the number of conference calls as defined in Table 1 ( $\Delta$ CALL). In Column 4 , we restrict the analysis to changes in the number of conference calls during the second-half of the event period. Columns 5 and 6 present results from regressing $\hat{\mathrm{b}}_{\mathrm{i} 2}$ on $\triangle 8 \mathrm{KCOUNT}$ and $\triangle \mathrm{CALL}$, respectively, relating the curvature of the quadratic beta estimate to firms' immediate disclosure responses. The control variables are measured as of fiscal year 2000 . The models include industry-fixed effects based on one-digit SIC codes and a binary indicator for Enron-related industries. The t-statistics are reported in parentheses and based on standard errors that are clustered at two-digit SIC level. $* * *\{* *\}(*)$ indicates significance at the $1 \%, 5 \%, 10 \%$ level in a two-sided test, respectively.

\begin{tabular}{|c|c|c|c|c|c|c|}
\hline & \multicolumn{2}{|c|}{$\Delta 8 \mathrm{KCOUNT}$} & \multicolumn{2}{|c|}{$\triangle \mathrm{CALL}$} & \multicolumn{2}{|c|}{$\hat{b}_{\mathrm{i} 2}$} \\
\hline & (1) & (2) & (3) & (4) & (5) & $(6)$ \\
\hline Constant & $\begin{array}{c}0.3157 * * * \\
(3.21)\end{array}$ & $\begin{array}{c}0.1103 * * * \\
(3.56)\end{array}$ & $\begin{array}{c}0.1143 \\
(1.39)\end{array}$ & $\begin{array}{c}0.0333^{*} \\
(1.69)\end{array}$ & $\begin{array}{c}-0.0049 \\
(0.18)\end{array}$ & $\begin{array}{c}-0.0009 \\
(0.03)\end{array}$ \\
\hline INIT_SHOCK & $\begin{array}{c}0.0637 * * \\
(2.19)\end{array}$ & & $\begin{array}{c}-0.0136 \\
(0.71)\end{array}$ & & & \\
\hline REM_SHOCK & & $\begin{array}{c}-0.0220 * * \\
(2.25)\end{array}$ & & $\begin{array}{c}-0.0085 \\
(1.34)\end{array}$ & & \\
\hline BETA_PRE & $\begin{array}{c}0.0412 \\
(0.76)\end{array}$ & $\begin{array}{c}-0.0154 \\
(1.28)\end{array}$ & $\begin{array}{c}-0.0157 \\
(0.44)\end{array}$ & $\begin{array}{c}0.0029 \\
(0.29)\end{array}$ & $\begin{array}{c}-0.1128 * * * \\
(16.15)\end{array}$ & $\begin{array}{c}-0.1127 * * * \\
(15.72)\end{array}$ \\
\hline LASSETS $_{2000}$ & $\begin{array}{c}-0.0724 * * * \\
(3.98)\end{array}$ & $\begin{array}{c}0.0211 * * * \\
\quad(3.52)\end{array}$ & $\begin{array}{c}-0.0114 \\
(0.82)\end{array}$ & $\begin{array}{c}0.0013 \\
(0.32)\end{array}$ & $\begin{array}{c}0.0177 * * * \\
\quad(3.95)\end{array}$ & $\begin{array}{c}0.0186^{* * *} \\
(4.15)\end{array}$ \\
\hline $\mathrm{ROA}_{2000}$ & $\begin{array}{c}0.2421 \\
(1.36)\end{array}$ & $\begin{array}{c}-0.1069 * * * \\
(3.39)\end{array}$ & $\begin{array}{c}-0.0434 \\
(0.79)\end{array}$ & $\begin{array}{c}-0.0081 \\
(0.33)\end{array}$ & $\begin{array}{c}0.0021 \\
(0.07)\end{array}$ & $\begin{array}{c}-0.0035 \\
(0.12)\end{array}$ \\
\hline DERATIO $_{2000}$ & $\begin{array}{c}0.1102 \\
(0.81)\end{array}$ & $\begin{array}{c}-0.0581 \\
(1.60)\end{array}$ & $\begin{array}{c}-0.0437 \\
(0.66)\end{array}$ & $\begin{array}{c}0.0269 \\
(0.85)\end{array}$ & $\begin{array}{c}-0.0426 \\
(1.47)\end{array}$ & $\begin{array}{c}-0.0457 \\
(1.57)\end{array}$ \\
\hline $\mathrm{MB}_{2000}$ & $\begin{array}{c}-0.0001 \\
(0.03)\end{array}$ & $\begin{array}{c}0.0010 \\
(1.17)\end{array}$ & $\begin{array}{c}0.0029^{*} \\
(1.95)\end{array}$ & $\begin{array}{c}0.0006 \\
(1.04)\end{array}$ & $\begin{array}{c}0.0004 \\
(1.26)\end{array}$ & $\begin{array}{c}0.0005 \\
(1.35)\end{array}$ \\
\hline $\mathrm{PPE} / \mathrm{TA}_{2000}$ & $\begin{array}{c}-0.0967 \\
(0.67)\end{array}$ & $\begin{array}{c}0.0001 \\
(0.00)\end{array}$ & $\begin{array}{c}-0.1373 \\
(1.38)\end{array}$ & $\begin{array}{c}-0.0136 \\
(0.28)\end{array}$ & $\begin{array}{c}-0.0852^{* *} \\
(2.19)\end{array}$ & $\begin{array}{c}-0.0867 * * \\
(2.23)\end{array}$ \\
\hline$\triangle 8 \mathrm{KCOUNT}$ & & & & & $\begin{array}{c}0.0247 * * \\
(2.63)\end{array}$ & \\
\hline$\triangle$ CALL & & & & & & $\begin{array}{c}0.0080 \\
(0.57)\end{array}$ \\
\hline Industry controls & YES & YES & YES & YES & YES & YES \\
\hline Observations & 1,793 & 1,793 & 1,793 & 1,793 & 1,793 & 1,793 \\
\hline R-squared & 0.0204 & 0.0335 & 0.0122 & 0.0085 & 0.0770 & 0.0745 \\
\hline
\end{tabular}




\section{Table 7}

\section{Analysis of market responses to the changes in the $10-\mathrm{K}$ filings}

Panel A presents an analysis of beta response from the event period to the post-report period: BRESPONSE $=$ BETA_EVT - BETA POST. The models include page changes in the $10-\mathrm{K}(\% \Delta \mathrm{PAGES})$ and control variables. LSIZE is the natural log of firm size as defined in Table 1. DERATIO is long-term debt scaled by total assets and MB is the market-to-book ratio as defined in Table 1. The control variables are measured as of fiscal year 2001. The changes in the controls are measured from 2000 to 2001. The t-statistics are reported in parentheses and based on standard errors that are clustered at the firm level. *** $\{* *\}(*)$ indicate significance at the $1 \%, 5 \%, 10 \%$ level (two-sided).

\section{Panel A: Post 10-K beta response}

\begin{tabular}{|c|c|c|c|}
\hline & $(1)$ & (2) & (3) \\
\hline Constant & $\begin{array}{c}-0.2543 * * \\
(2.32)\end{array}$ & $\begin{array}{c}-0.2957 * * * \\
(2.66)\end{array}$ & $\begin{array}{c}-0.2062^{*} \\
(1.77)\end{array}$ \\
\hline$\% \triangle \mathrm{PAGES}$ & $\begin{array}{c}0.1726^{* * * *} \\
(2.82)\end{array}$ & $\begin{array}{c}0.1767 * * * \\
(2.81)\end{array}$ & $\begin{array}{c}0.1649 * * * \\
\quad(2.58)\end{array}$ \\
\hline LSIZE $_{2001}$ & $\begin{array}{l}0.0106 \\
(1.03)\end{array}$ & $\begin{array}{l}0.0106 \\
(0.93)\end{array}$ & $\begin{array}{l}0.0166 \\
(1.43)\end{array}$ \\
\hline DERATIO $_{2001}$ & & $\begin{array}{c}0.0353 \\
(0.35)\end{array}$ & $\begin{array}{c}-0.0133 \\
(0.13)\end{array}$ \\
\hline $\mathrm{MB}_{2001}$ & & $\begin{array}{c}-0.0003 \\
(0.04)\end{array}$ & $\begin{array}{c}-0.0013 \\
(0.19)\end{array}$ \\
\hline$\Delta \mathrm{LSIZE}$ & & & $\begin{array}{c}-0.0438 \\
(0.65)\end{array}$ \\
\hline$\triangle$ DERATIO & & & $\begin{array}{c}0.3148 \\
(1.36)\end{array}$ \\
\hline$\Delta \mathrm{MB}$ & & & $\begin{array}{c}0.0609 \\
(0.88)\end{array}$ \\
\hline Industry controls & YES & YES & YES \\
\hline $\begin{array}{l}\text { Observations } \\
\text { R-squared }\end{array}$ & $\begin{array}{c}1,794 \\
0.0168\end{array}$ & $\begin{array}{c}1,700 \\
0.0178\end{array}$ & $\begin{array}{c}1,641 \\
0.0201\end{array}$ \\
\hline
\end{tabular}




\section{Table 7 (continued)}

\section{Analysis of market responses to the changes in the 10-K filings}

Panel B presents models the short-window abnormal volume response around the $10-\mathrm{K}$ filing on the percentage change in $10-\mathrm{K}$ pages and control variables. Abnormal volume is defined as stated in Section 6 . We include the abnormal volume generated by last year's 10-K filing as a control (ABN_VOL). FIL_DELAY measures the number of days the $10-\mathrm{K}$ filing is delayed relative to the filing dates in 2000, adjusted for its delay relative to 1999. LSIZE is the natural log of firm size as defined in Table 1, DERATIO is long-term debt scaled by total assets and MB is the market-to-book ratio as defined in Table 1. The control variables are measured as of fiscal year 2001. The regression models include industry fixed effects. The t-statistics are reported in parentheses and based on standard errors that are clustered at the firm level. $* * *\{* *\}(*)$ indicate significance at the $1 \%, 5 \%, 10 \%$ level (two-sided).

\begin{tabular}{|c|c|c|c|}
\hline & (1) & (2) & (3) \\
\hline \multirow[t]{2}{*}{ Constant } & 1.0010 & 0.9116 & 0.8903 \\
\hline & $(1.62)$ & (1.34) & $(1.47)$ \\
\hline \multirow[t]{2}{*}{$\% \triangle \mathrm{PAGES}$} & $0.1040 *$ & $0.1127 *$ & $0.1138^{*}$ \\
\hline & (1.66) & (1.71) & (1.83) \\
\hline \multirow{2}{*}{$\mathrm{ABN}_{-} \mathrm{VOL}_{2000}$} & 0.0465 & 0.0316 & 0.0323 \\
\hline & $(1.62)$ & $(1.10)$ & $(1.15)$ \\
\hline \multirow{2}{*}{ FIL_DELAY $_{0199}$} & -0.0015 & -0.0013 & -0.0022 \\
\hline & $(0.86)$ & $(0.66)$ & $(1.29)$ \\
\hline LSIZE $_{2001}$ & $-0.0242 * *$ & $-0.0265^{* *}$ & \\
\hline $\mathrm{MB}_{2001}$ & $(2.40)$ & $\begin{array}{c}0.0037 \\
(0.39)\end{array}$ & \\
\hline DERATIO $_{2001}$ & & & $\begin{array}{l}0.1379 \\
(1.47)\end{array}$ \\
\hline LASSETS $_{2001}$ & & & $\begin{array}{c}-0.0357 * * * \\
(2.89)\end{array}$ \\
\hline $\mathrm{ROA}_{2001}$ & & & $\begin{array}{l}0.1681 \\
(1.36)\end{array}$ \\
\hline Industry controls & YES & YES & YES \\
\hline Observations & 1,389 & 1,316 & 1,361 \\
\hline $\mathrm{R}$-squared & 0.0173 & 0.0174 & 0.0205 \\
\hline
\end{tabular}

